\title{
ARTIFICIAL POKA-YOKE INCREASES PROCESS RELIABILITY VIA A HYBRID OF THE NEURAL NETWORK WITH ARIMA RESULTS
}

\author{
AHMED M. ABED ${ }^{1}$, SAMIA ELATTAR ${ }^{2}$, TAMER S. GAAFAR ${ }^{3}$ \& FADWA ALROWAIS ${ }^{4}$ \\ ${ }^{1}$ Department of Industrial Engineering, Zagazig University, Egypt \\ ${ }^{2}$ Department of Industrial and Systems Engineering in College of Engineering, Princess Nourah bint \\ Abdulrahman University, Riyadh, KSA \\ ${ }^{1,2}$ Department of Industrial Engineering, AIET, Alex, Egypt \\ ${ }^{3}$ Department of Computer and systems Engineering, Zagazig University, Egypt \\ ${ }^{4}$ Department of Computer Sciences in College of Computer and Information Sciences, Princess
}

Nourah bint Abdulrahman University, Riyadh, KSA

\begin{abstract}
A product's sustainability fails if its standard function deviates from the desired working conditions (i.e., by making an unscheduled stop), which makes less competitive. This study aims to develop a smart autonomation system via closer monitoring of the time series' forecasting model of deviation behavior to enable it to stop for maintenance when needed. The proposed methodology (Artificial Poka-yoke; APY) achieves the objective via two sequential phases focusing on improving the operation's performance, (deviation behavior to stop the machine before antagonizing HBL's essential elements). The methodology alters the ARIMA's trajectory and its error, as a Neural-Network (NN) inputs model is used to simulate them in the second phase to enhance its accuracy by comparing minimized MAE and RMSE values, through 72 trials and revealing the Poka-yoke index error. An APY approach is adopted for an electrical combustion engine to enhance its reliability level, based on intake control, unloaders valve and rifle drilled. The proposed methodology demonstrates its ability to forecast energy consumption related to that actually generated effectively and accurately. The methodology guarantees a reduction in downtime and waste by $0.71 \%$ as a profit saving via ARIMA $(2,1,1) x(0,1,1)_{6}$ supported with a neural network to create smart operation.
\end{abstract}

KEYWORDS: Lean Manufacturing, Poka-Yoke, ARIMA, Neural Network Model \& Deviation Forecasting

Received: Feb 22, 2020; Accepted: Mar 12, 2020; Published: Apr 06, 2020; Paper Id.: IJMPERDAPR202092

\section{INTRODUCTION}

Deep-Lean is a modern interdisciplinary concept which aims to eliminate the waste at the sub-causes level during manufacturing or services related to the TBL (Triple Bottom Line) elements and adopts the motto "environment, machine and people' are friends". It also aims to evaluate and manage the performance of operations [2] and to increase reliability, availability and reducing environmental risk via reducing fuel consumption. In Egypt, the governorate objects to increase its exports ad satisfy customer via growing interest in the reliability concept, according to which the process is given the ability to stop working if its output will harm one of the TBL elements, thus focusing on increasing the processes' ability to detect mistakes and correct them immediately. Poka-yoke (i.e., reliability philosophy) is a mistake-proofing approach proposed by Shigeo Shingo to enhance the reliability concept, which aims to eliminate any problem created by deviating from product working conditions, by preventing or correcting mistakes as early as possible. Every working span of products' process is challenged with 
many errors incidence at any time [17], using Poka-yoke, the deviation is moved toward the rejection zone under working conditions, avoiding harm to any of TBL elements.

Since the end of the 20th century, the reduction of fuel consumption has been at the top of every manufacturers' agenda, via control the function faulty carburetor valves in of any combustion engine [26] (i.e., used in vehicles, steams, airplane ... and so on). The fuel consumption will be reduced by controlling carburetor's valve actuation behavior, that prohibits the fuel stream in its tracks, as a perface to drainage through engine shutting [34]. This will help in maintaining the reliability of this valve during its working life with minimum deviation from standard specifications. Therefore, an interdisciplinary approach advocates contributing to the sustainability of TBL keep down, with good function via its design improvement of these valves to be interactive and subjected to kaizen [32] to reduce pollution. Poka-yoke is a technique that aims to reliably monitor the deviations from standard limits of working conditions over a long time period, which calls for developing an accurate methodology for prediction of malfunction. In the case of a combustion engine, it is extremely difficult to achieve a zero-leakage consumption rate while working in a large environment that many manufacturing functions for every device's components. The units influence the fuel consumption the of the combustion engine shown in Figure-1: the motor, compressor/cylinder unit and valve unit that are all interested in check the methodology of the proposed prediction process. Ongoing monitoring becomes viable by predicting process deviation [6] and solutions can be discovered for process reliability through analysis of the malfunctions.

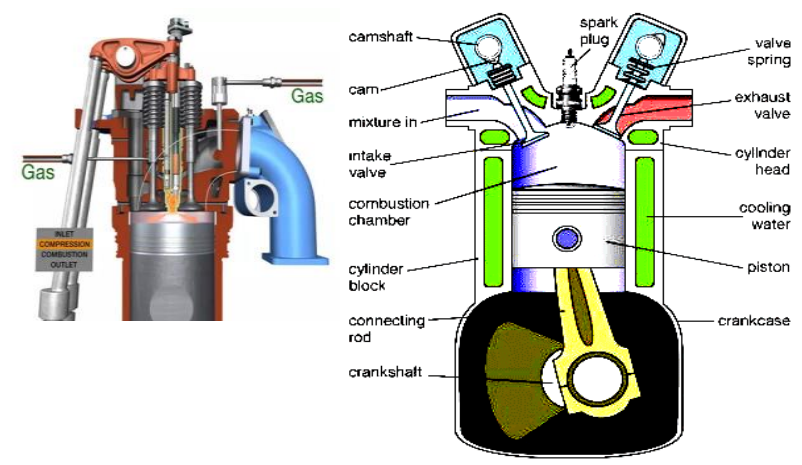

Figure 1: Hydraulic Generator Components.

The monitoring procedures are carried out by measuring specific functional factors modeled with ARIMA supported with NN to enhance reliability level. The operation's $C_{p}$ is a popular level parameter that explains the reliability standard, but this is not enough in cases that include human interventions [1]. Thus, the use of the Poka-yoke index is suggested to evaluate the reliability in effect on the process on the social, economic and environmental aspects together (i.e. the TBL elements). Any deviation during working operation must be addressed by stopping the process until maintenance done. Shingo suggests three Poka-yoke categories: judgmental, informative and at source [4]. Poka-yoke sorts and prods the defective products that are deviating from the acceptable standards, without going into working methods to tackle the causes of their defects. Informative Poka-yoke collects feedback information on the defects (i.e., malfunction) to reduce their rates gradually by improving the manufacturing method [34]. Informative Poka-yoke includes sampling checks in SQC/SPC. The three types seek information about lifetime reliability, which is the working time of every part in the process without deviation from standard working condition, CL. Therefore, it is necessary for researchers to concentrate on waste sub-causes, particularly with regard to deviation from standards, which is called the Deep-lean level of artificial Poka-yoke framework, as illustrated below in Figure 6.1. The device components explained 
in Figure 1 made up Piston moving forth and back in a cylinder, with discharge and suction valves and lead to increased fuel consumption in function failure [6] due to bad in a hole's radius or thickness dimensions. The discharge and suction valves close and open according to pressure variations among the cylinder and entry or exit manifolds respectively. Pokayoke is significant case in superior schedule of investments.

Artificial Poka-Yoke (APY) is a suggested methodology that guarantees a long reliability lifetime, by stopping working and correcting the deviation if it is possible or changing the part to ensure the safety of TBL elements [14, 26]. The deviation has non-linear behavior. Therefore, in this research, the reliability lifetime was forecast via ARIMA aided with NN (which monitors a relative risk of an output by studying the significant parameters of its sub-causes at the minor level of lean implementation) for measuring the amount of deviation created during working. ARIMA, created by Box and Jenkins in 1970 [9] was based on observations created from first day of working and consists of a dataset which can be used to forecast the deviation behavior for creating effective control in a specific working span and time based on an APY framework, which has the advantage of improving the prediction accuracy (Luxhoj, et al., 1996 [22]; Balkin \&Ord 2000; Medeiros \&Veiga, 2000; Tseng et al., 2002 [35]; Zhang, 2014 [46]; Chen \& Wang 2007 [12]; Isinkaye et al., 2015 [19]; Qiu\& Song, 2016 [31]).

\subsection{ARIMA Modeling Approach Needed in Phase-1}

The ARIMA $(p, d, q)$ forecasting model of fuel consumption can be represented by general terms, as follows:

$$
y_{t}=\mu+\sigma_{1} y_{t-1}+\sigma_{2} y_{t-2}+\cdots+\sigma_{p} y_{p-2}+\varepsilon_{t}-\theta_{t} \varepsilon_{t-1}-\cdots-\theta_{q} \varepsilon_{q-1}
$$

where $p$ is the autoregressive number and $q$ is the number of lagged forecast errors in the prediction equation, based on plots of the AutoCorrelation Function (ACF) and Partial AutoCorrelation Function (PACF) [29].

\subsection{Artificial Neural Network Modeling needed in phase-2}

The (NN) model is characterized by emulating the nonlinear or linear data behavior accurately [7]. The $\mathrm{NN}$ is determined by the characteristics of this data fed forward from ARIMA and DOE optimizer outputs to work through some of the hidden layer related to time series, which is formulated as follows:

$$
y_{t}=w_{0}+\sum_{j=1}^{q} w_{j} * g_{x}\left(w_{0 j}+\sum_{i=1}^{p} w_{i j} * x_{t, i}\right)+\varepsilon_{t}
$$

Where $w i j(i=\mathbf{0 , 1 , 2 , \ldots , \mathbf { p }})$ and $w j(j=0, \mathbf{1 , 2 , \ldots , q})$ are the connection weight parameters. The terms $p, q, \varepsilon t, w 0$ and $w 0, j$ and $\mathrm{g}_{x}$ are the number of input nodes, the number of hidden nodes, error term and $g_{x}=\frac{1}{1-e^{-x}}$, while the time series model for linear and non-linear output data, formulated as $y_{t}=l_{t}^{*}+n l_{t}^{*}$. where $l_{t}^{*}$ is linear, while $n l_{t}^{*}$ is nonlinear data output from ARIMA.

APY consists of two sequential phases; phase-1 is to obtain a linear model from ARIMA, while the error obtained from phase-1 behaves as nonlinear, $\varepsilon_{\mathrm{t}}=\mathrm{y}_{\mathrm{t}}^{*}+\hat{y}_{\mathrm{t}}^{*}$. Therefore, the second phase (phase-2) is created to tackle the nonlinear predictable and its error via the NN model follows $\epsilon_{\mathrm{t}}=f\left(\epsilon_{\mathrm{t}-1}^{*} \ldots \cdot \hat{\epsilon}_{\mathrm{t}-n}^{*}\right)+\omega_{\mathrm{t}}$, where $f$ is a nonlinear function, and $\boldsymbol{\omega} t$ is a random weight variable. The APY forecasting model would then be written as: 


$$
y F_{\mathrm{t}}=(1+n) F_{\mathrm{t}} .
$$

The accuracy of the reliability is based on both linear and nonlinear characteristics' behavior for the available series of deviations. Two key performance indicators are used to test the accuracy: the Mean Absolute Error (MAE) and Root Mean Square Error (RMSE), which are calculated to compare the results' accuracy, as follows:

$$
\begin{aligned}
& \text { MAE }=\frac{\left|\sum_{i=1}^{n} y_{i}-y F_{t}\right|}{n} . \\
& \text { RMSE }=\sqrt{\sum_{i=1}^{n}\left(y_{i}-y F_{t}\right)^{2} / n}
\end{aligned}
$$

Each dataset collected concentrates on a specific working condition to reflect its deviation behavior [6, 18]. The proposed APY model outperforms current models, because it forecasts by giving the amount consumption (in terms of its deviation) [10, 17], and whether this was acceptable or not.

\section{COMBUSTION ENGINE FUNCTIONALISM}

The experimental study concentrated on; ${ }^{1)}$ the valve plates as a cause fuel consumption instability, and ${ }^{2)}$ The rotary valve [2]. The analysis presented here matches to an indoor combustion engine of a cylinder space $6.64 \mathrm{~cm} 3$, active with R134a and a nominal frequency of $50 \mathrm{~Hz}$. Suction, pressure and discharge operations are the central operations of the selected device, which are carried out during valve plate slots and discharge slots [2]

\subsection{Experimental Design}

This study is aimed to increase the reliability of the processes to avoid extra fuel consumption and back off the torque power, if worked in poor condition. The experiments were focused on valve unit of intake and Safe-Q-lube unloaders and cast-iron valve seats, which included the valve plates, valve gaskets, cylinder head and muffler.

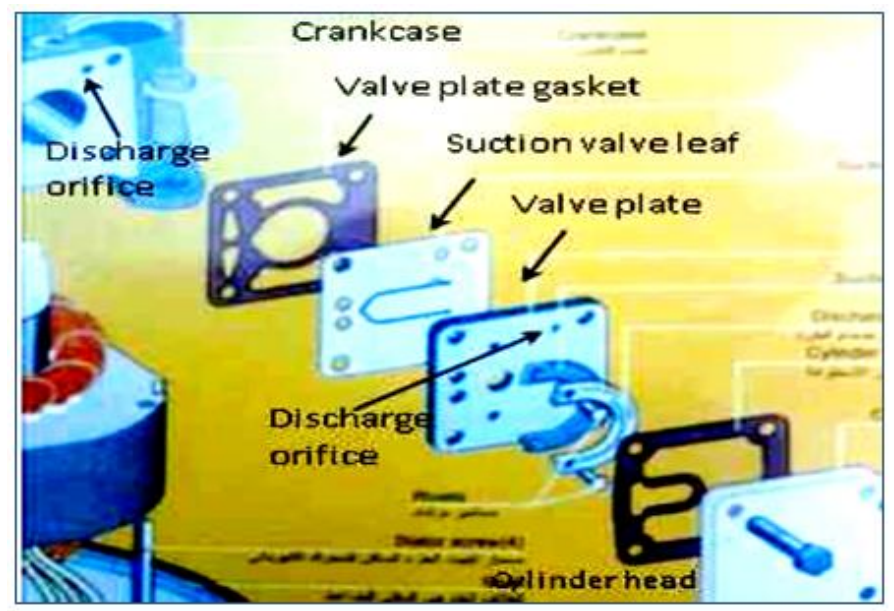

Figure 2: Schematic Valve Unit of Generator. 


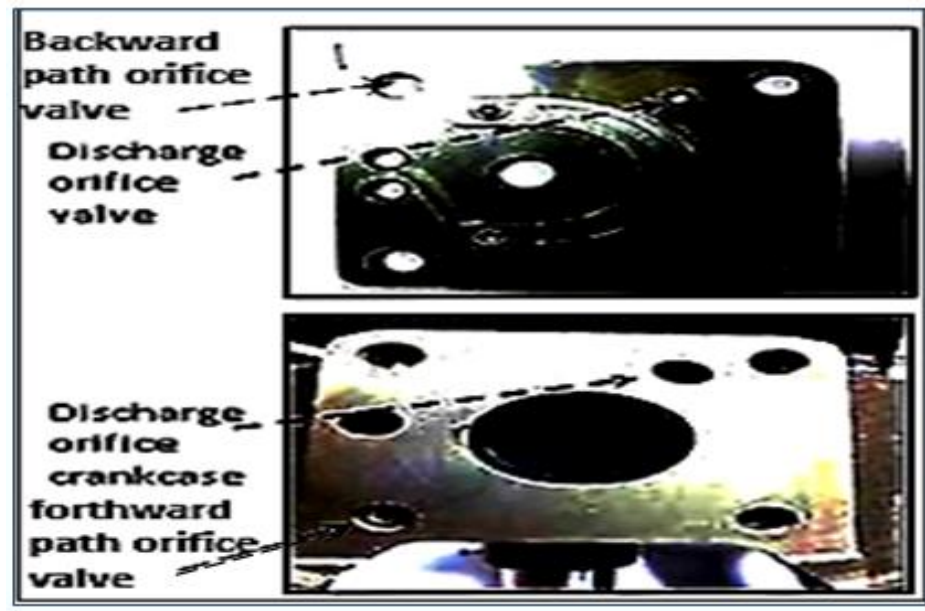

Figure 3: Discharge Orifice of Valve Plate and Crankcase.

The selected control factors (i.e. tolerance limit) for valve units are the valve thickness

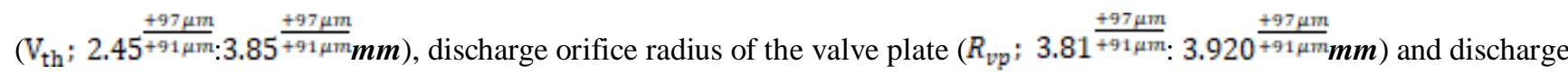

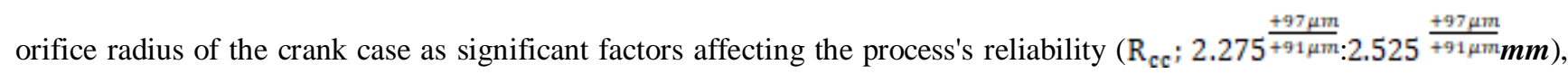
as illustrated in Figure 2 and Figure 3. Any deviations in these limits that cause extra fuel consumption, which is measured in $\mathrm{mm}^{3} \mathbf{x} 10^{3} / \mathrm{sec}$, and reduce its torque are recorded in Table 2. The experimental study handled the real data of 24 combustion engines, based on eight samples for a two-level set of DOE $2^{\mathrm{k}} / 3$ replicates. All samples were produced and examined maintaining the actual manufacturing environment the remnant of the parameters of other parts. Figure 4 illustrates the important factors that have to be planned though valve plate or crankcase processing to conserve the fuel consumption $\left(<0.2 \mathrm{~mm}^{3} \times 10^{3} / \mathrm{sec}\right)$. Figure 5 suggests that the valve thickness should be controlled at $2.75 \mathrm{~mm}$, and the discharge orifice of the valve plate radius should be $3.0_{m m}$, whiles the discharge orifice of the crankcase should be $2.525 \mathrm{~mm}$ (all these values with tolerance in $\mathrm{mm}$ ). The operational effectiveness is based on four key factors [rotational speed, altitude path, fuel feed rate and thickness of valve]; the rotational speed which is measured in rpm, is recommended to be constant, and its effect on the average altitude path of $21.4 \mathrm{mpm}$, which is matched with [457:459 rpm], whereas the fuel feed rate $[8: 12 \mathrm{~cm} 3 / \mathrm{sec}]$ is based on the altitude path length (second factor), and the thickness of the valve. The Pareto chart cleared in Figure 4-1 explains that variations build on the way that rotational speed intersects with feed and thickness. Monitoring the operational deviation vs. time, for every significant factor, as shown in Figure 5; fuel to be conserved and be prevented for the extra fuel consumption.

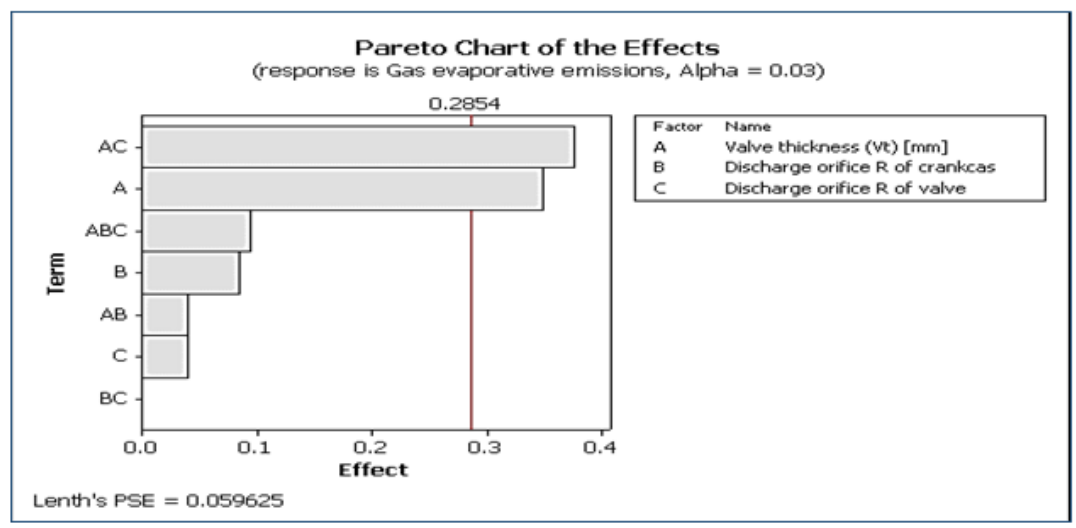

Figure 4: The Important Factors cause Violate Euler's Equation. 


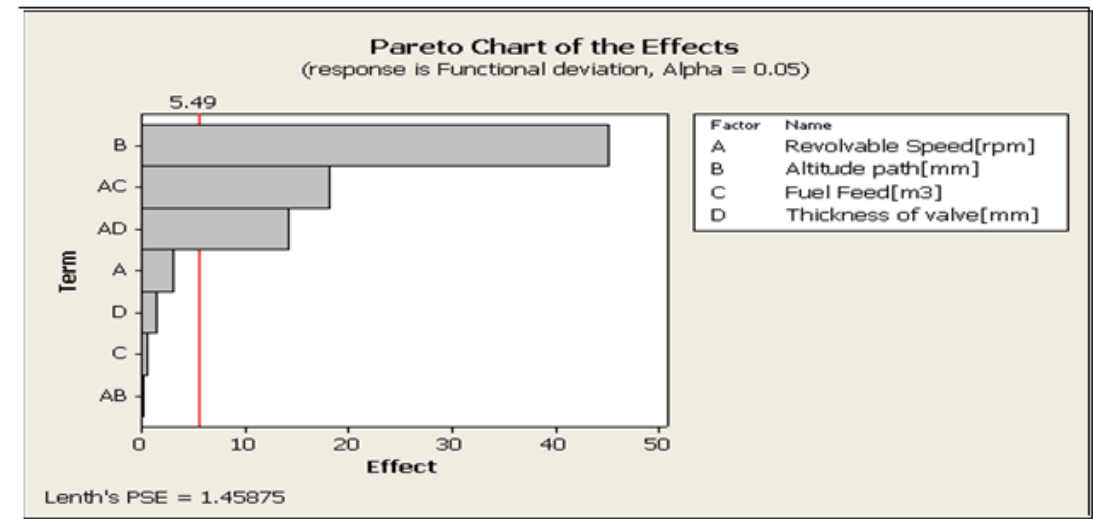

Figure 4.1: The Important Factors cause the Functionalism Deviation.

\section{PROPOSED [APY] FRAMEWORK}

The proposed framework detailed in Figure 6.1 focuses on predicting the deviation during the working period using ARIMA, then feeding the dataset with expected values of its errors in nonlinear behavior based on the NN model, to increase the accuracy of predicting its reliability.

The leakage rate, based on a Poka-yoke index derived from Euler's turbine equation based on, where the power output collected in Table 2, $P=\omega T=\omega \rho Q\left(r_{\text {in }} q_{\text {in }} \operatorname{Cos} \beta_{\text {in }}-r_{\text {out }} q_{\text {out }} \operatorname{Cos} \beta_{\text {out }}\right)$ as illustrated in Figure 6 and PYi $=f(\varphi, \theta)$, which is a function of the consumption amount $\varphi \in P$ required $\left(\varphi=\sum_{y_{i}}^{\varepsilon} D O E_{i}+\varepsilon\right)$, where $\varepsilon$ is the deviation, appears in Figures 5 and 5-1 $(\varepsilon=1-d)$ and the output feed $\mathrm{NN}$ as a function of $\varphi(\mathrm{NN}=f(\varphi))$, whereas the second parameter

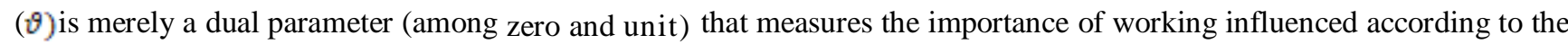
integrated DOE equations. Higher rates of $\vartheta$ increase the variations and command to a major stage of leakage occurring, and lower rates lead to the opposite, and are formulated as Eq. (5) and Eq. (5.1) to fade any trend in malfunction behavior for each of the significance factors shown in Figures 4, 4-1 and 6-1 and determine the best working. The parameters shared in the leakage, rates that appeared, as illustrated in Figure 6.2 according to $P Y_{\mathrm{i}}=f($ significant limits $(k)$, uptime, lifetime) and its significant factors $=f[$ (Temperature, fluid flow rate, fluid velocity, fluid density)|target $]$ and were calculated according Eq.5 for fuel $\left[6.8: 8 \mathrm{~mm}^{3} / \mathrm{sec}\right]$, for working factors to be $[85: 115 \mathrm{~mm}]$ and for valves to be $\left[0: 30 \times 10^{3} \mathrm{~mm}\right]$.

$$
\begin{aligned}
& P Y_{i}(t+\delta t)=f(\varphi) \\
& =\left[\ln \left[(1-\vartheta) \psi_{s}(t)+\frac{\vartheta^{2}}{z} \sum_{s^{\prime} \sim s} \Delta \psi_{s^{t}}(t)\right](1-\omega \delta t)+\theta E_{s}(t)\right] * y_{t} \\
& \Delta \psi_{s}(\boldsymbol{t})=\frac{\left(\sum_{s^{\prime} \sim v_{s}} \Delta \psi_{s^{t}}(\boldsymbol{t})-z \psi_{s}(\boldsymbol{t})\right)}{\mu^{2}}
\end{aligned}
$$

where $\Delta$ is the discrete Laplacian for difference between consumption at $\mathrm{t}$ and $\mathrm{t}-1$ period and $\mu$ is the mean value for $z$ significant factors. The variations for 6 lag [34] to dissolve the way, as explained in Figures 14, 15 and 16, the datum 
composed have to be normalized through rolled up and squared | logarithmic to trial its impact with time variations to stop at a certain time for protecting TBL elements.

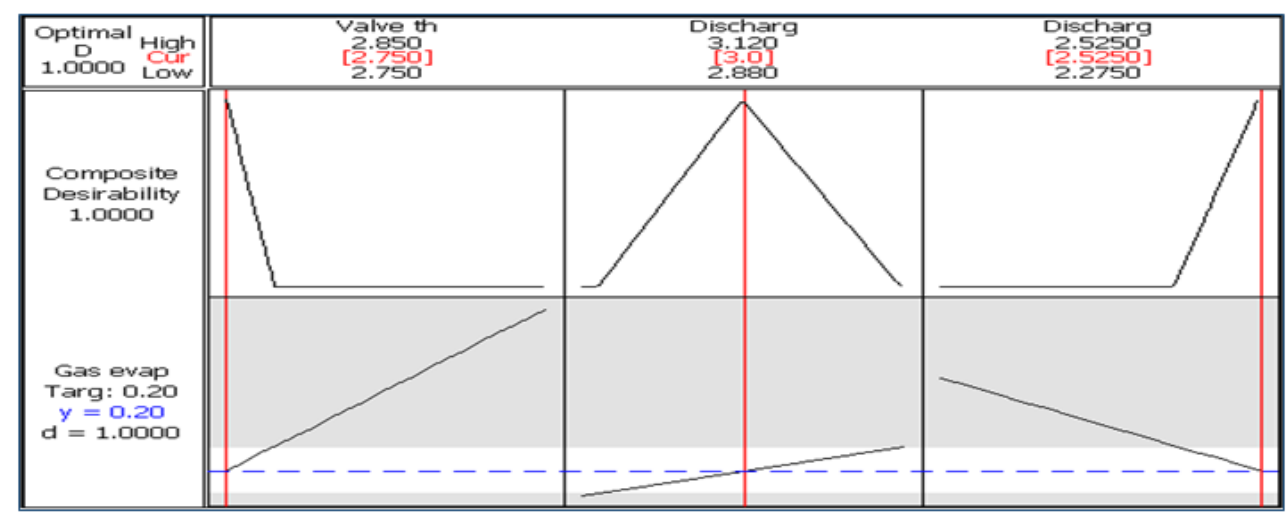

Figure 5: The Recommended Rates of Important Factors that Reduce the Fuel Consumption.

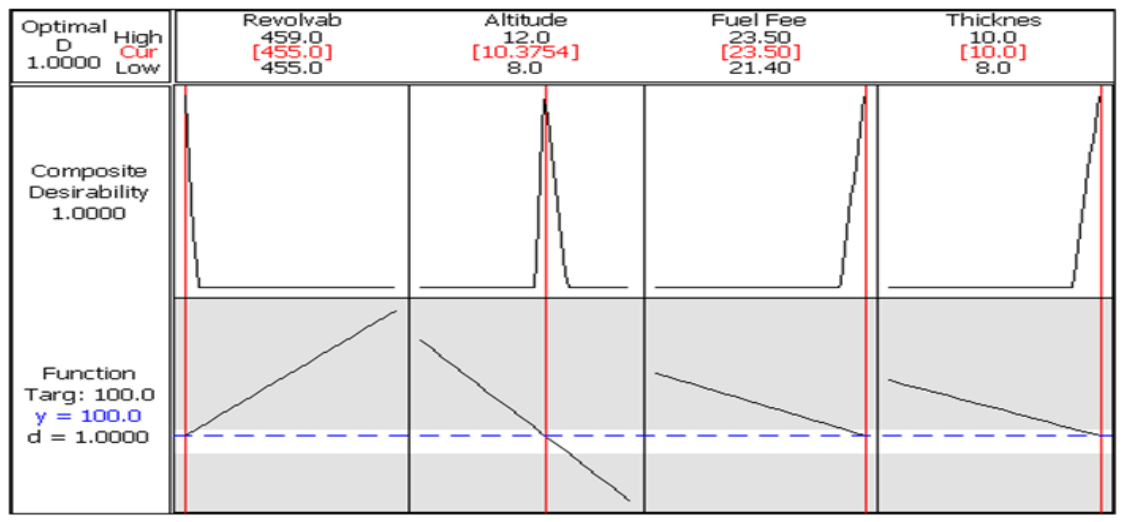

Figure 5.1: The Recommended Rates of Important Factors that Besiege the Deviation.

Table 1: The Fuel Consumption with $\mathrm{mm}^{3} / \mathrm{sec}$ for 33 Months

\begin{tabular}{|c|c|c|c|c|c|c|c|c|c|c|c|c|}
\hline & $M_{12}$ & $M_{16}$ & $\mathbf{M}_{19}$ & $\overline{M_{23}}$ & $\mathbf{M}_{25}$ & $\mathbf{M}_{27}$ & $\mathbf{M}_{28}$ & $M_{29}$ & $M_{30}$ & $\mathbf{M}_{31}$ & $M_{32}$ & $M_{33}$ \\
\hline & $\sigma_{\mathrm{s}}$ & $\sigma_{\mathrm{s}}$ & $\sigma_{\mathrm{s}}$ & $\sigma_{\mathrm{s}}$ & $\sigma_{\mathrm{s}}$ & $\sigma_{\mathrm{s}}$ & $\sigma_{\mathrm{s}}$ & $\sigma_{\mathrm{s}}$ & $\sigma_{\mathrm{s}}$ & $\sigma_{\mathrm{s}}$ & $\sigma_{\mathrm{s}}$ & $\sigma_{\mathrm{s}}$ \\
\hline 1 & 79.47 & 59.31 & 94.24 & 117.02 & 133.54 & 129.78 & 146.72 & 9.4 & 153.95 & 128.47 & 135.54 & 119. \\
\hline 2 & 65 & 9.3 & 97.43 & 11689 & 12 & $\partial^{*}$ & 12451 & $1+2$ & 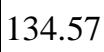 & 110. & \begin{tabular}{|l}
145.7 \\
\end{tabular} & 136.52 \\
\hline 3 & 60.97 & & 117.65 & 84.39 & 126 & 141.11 & 120.22 & & {$[122.6]$} & 140.95 & 139.19 & 55 \\
\hline 4 & 9.4 & 0. & 20.1 & 2.3 & 127.8 & 142 & 124 & 12 & 122 & 138 & 125 & 14 \\
\hline 5 & 70 & 7238 & 02 & 82 & 128. & 12 & 14 & 14 & 12 & $14 \varepsilon$ & 127 & 11 \\
\hline 6 & 6.41 & 4.39 & 123.1 & 84.83 & 125.9 & 136.72 & 124.3 & 124. & 127.0 & 128.1 & 129.8 & 136.2 \\
\hline
\end{tabular}

The local dataset adopts a neural-network model and considers the second phase of the proposed conceptual framework APY, as illustrated in Figure 6-1 and defined in Table 2. Table 1 illustrates one of the outputs measured and expresses the fluid_flow_rate $\mathrm{mm}^{3} / \mathrm{sec}$ and other fuel consumption/sec. Figure-7, which records some of the statistical frequencies [15] of deviation values, $\sigma_{\mathrm{s}}($ deviation), if the important factors explained in Figure 4-1 are neglected. The $\sigma_{\mathrm{s}}$ raised the error proceeding (i.e., the variation is reflected as a mirror for malfunction in the form of backward and forth, movements and burning) and $\boldsymbol{k}$ expresses the span of variation (significant limits according to the Pareto chart), which have 
maximum probability of deviation appearing.

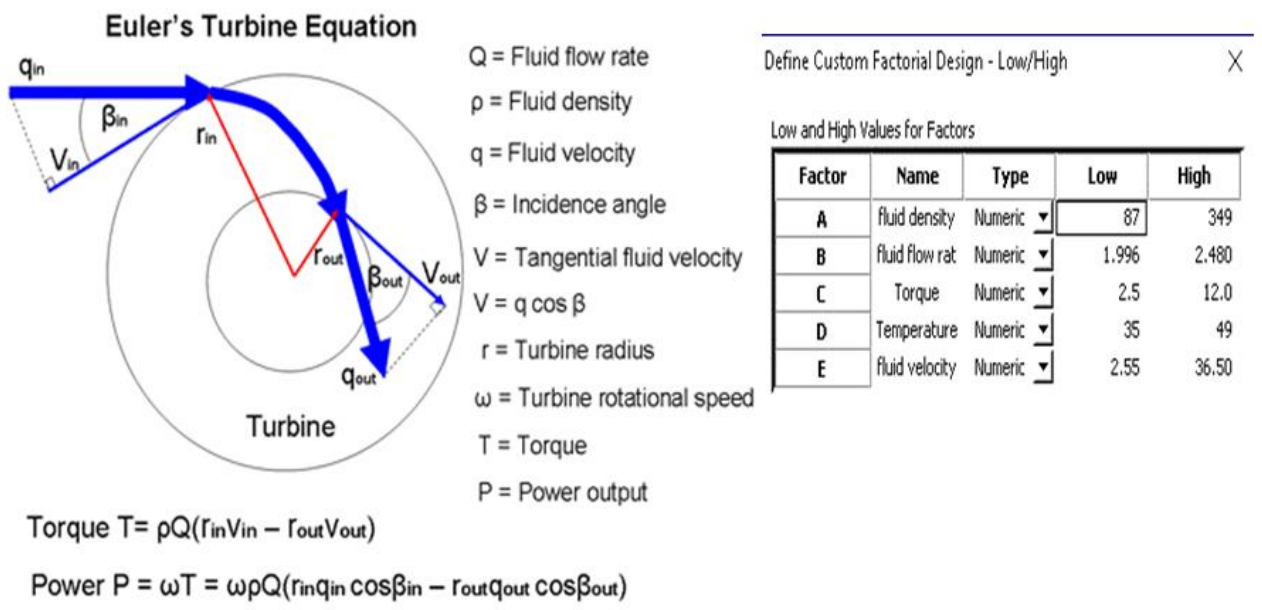

Figure 6: Euler

Figure 6: Euler's Turbine Equation's

The data introduce the variation's span range of 72 trials over 33 uptime months (i.e., the part must be replaced by newest one) with $\left(\sigma_{\mathrm{s}} ; \mathrm{mm}\right)$, as shown in Table 2 (Location A). As stated in Figures-3 and 7, the medium variation in fuel consumption is $113,414 \mathrm{~mm}^{3} / \mathrm{sec}$, where the minimum was $69 \times 10^{3} \mathrm{~mm}^{3} / \mathrm{sec}$ in a month (12) and the maximum was $155,46 \times 10^{3} \mathrm{~mm}^{3} / \mathrm{sec}$ in the month (33), which increased by $0.73 \%$ and deviated by about $\boldsymbol{m}$ by $24,08454 \times 10^{3} \mathrm{~mm}^{3} / \mathrm{sec}$ (leading to leakage in the part's function), the accepted variation range for the fuel consumption is $0.76<\boldsymbol{P} \boldsymbol{Y}_{\mathrm{i}}<1.56 \times 10^{3}$. These rates indicate the Heterogeneity of collected data, but according to the T-test, it clarified normal distribution. The data were analyzed at other locations (i.e., B, C and D), as illustrated in Figure 7.

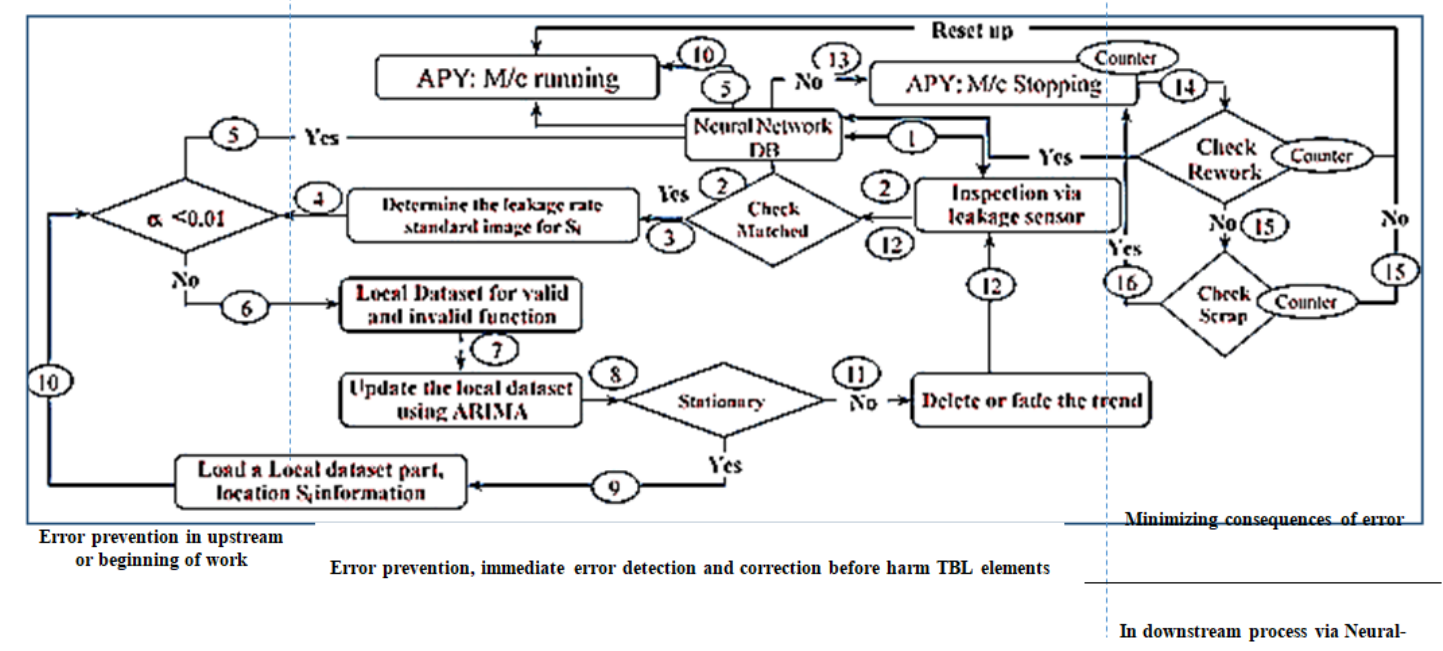

Figure 6.1: The APY Conceptual Framework.

Table 2: APY (APY) Cycling Functions Appeared in Figure 6.1

\begin{tabular}{|c|l|}
\hline NO. & \multicolumn{1}{c|}{ Action } \\
\hline 1 & Inspection of fuel consumption sensors especially forfluid_flow_rateandfluid_density \\
\hline 2 & Check matched within standard limits control \\
\hline 3 & Determine the leakage rate for fuels per sec \\
\hline 4 & Check for variation span $\sigma_{\mathrm{s}}$ \\
\hline
\end{tabular}




\begin{tabular}{|c|l|}
\hline 5 & $\begin{array}{l}\text { Create the central dataset for } \sigma_{\mathrm{s}} \text { for every fuel output value and expect via ARIMA the } \\
\text { future value with time series }\end{array}$ \\
\hline 6 & DB for validate the process to continuo or invalid and make query \\
\hline 7 & Send Query to APY methodology in central database based on ARIMA \\
\hline 8 & Check stationary if the $\sigma_{\mathrm{s}}<0.01$ (functional analysis) or not \\
\hline 9 & Update the input information with error value \\
\hline 10 & Analysis the ARIMA and its error via Neural Network \\
\hline 11 & If the observation not stationary, Delete the fade of the trend observed \\
\hline 12 & Forecasting the next consumption via Neural-Network \\
\hline 13 & Send forecasted $\sigma_{\mathrm{s}}$ in $m m$ for APY methodology in central dataset $\left(\mathrm{x}_{3}\right)$ \\
\hline 14 & APY approval if $\sigma_{\mathrm{s}}<0.01$ from central dataset to stop for rework \\
\hline 15 & $\begin{array}{l}\text { APY action; }\left[\text { Send data of stopping (if } \sigma_{\mathrm{s}}>0.01\right) \mid \text { continuo otherwise] for the three } \\
\text { significant outputs and calculate the process capability }\end{array}$ \\
\hline 16 & Count the generator downtime and reliability value \\
\hline 17 & Continuo the APY cycle \\
\hline
\end{tabular}

The same data table was collected for all the DOE's significant factors illustrated in Figures 4, 4-1, 6-1, through three different sensors to feed the dataset with data used in forecasting deviation behavior.

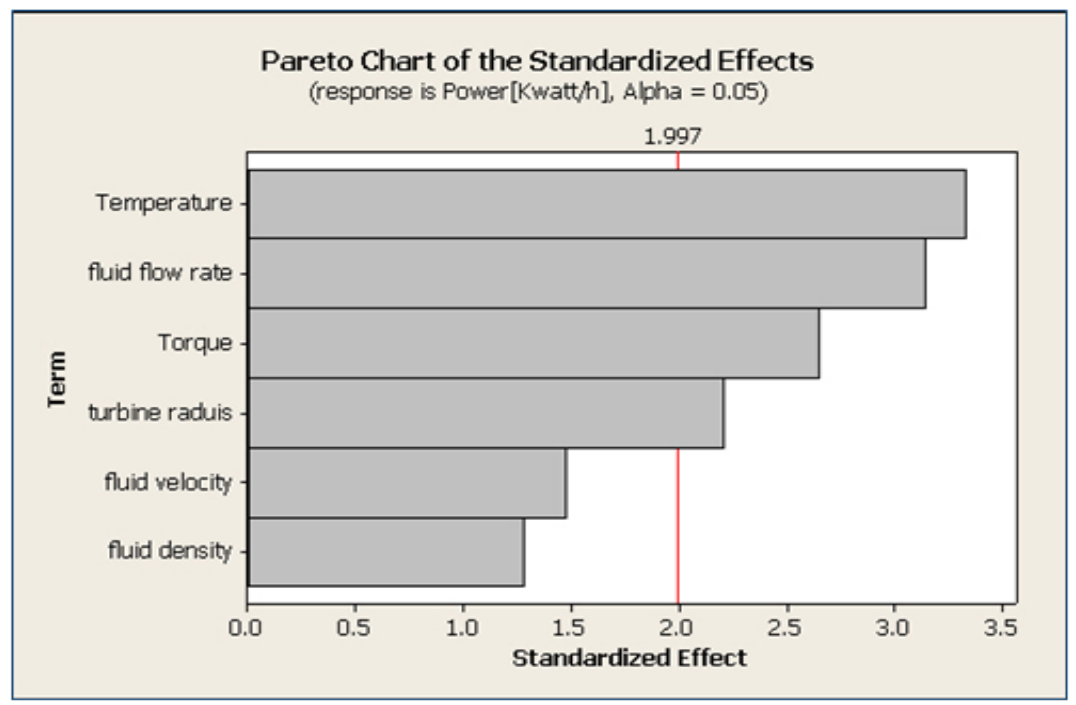

Figure 6.2: Pareto Chart of Gained Power.

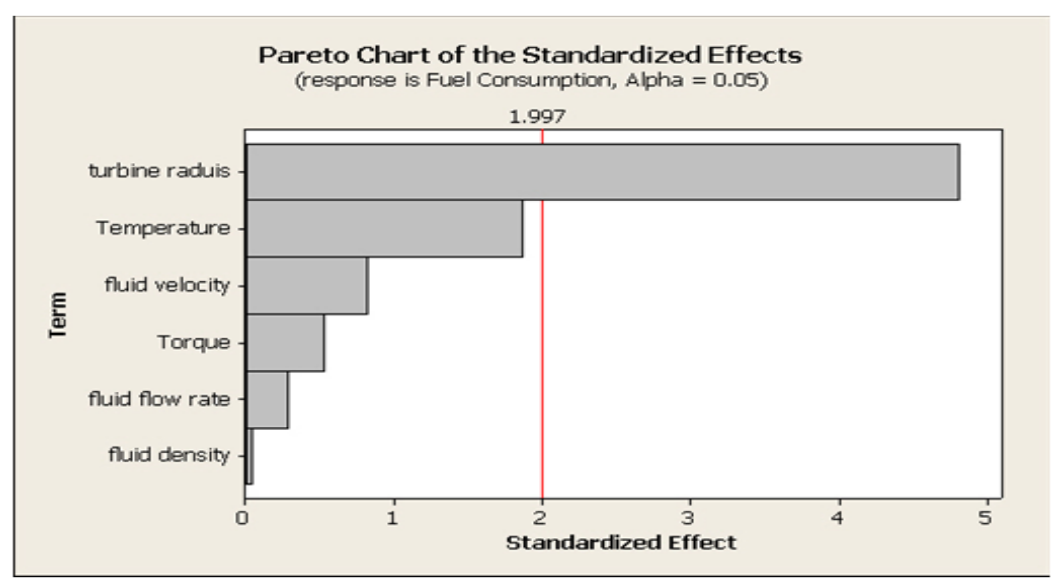

Figure 6.3: Pareto Chart of Fuel Consumption. 


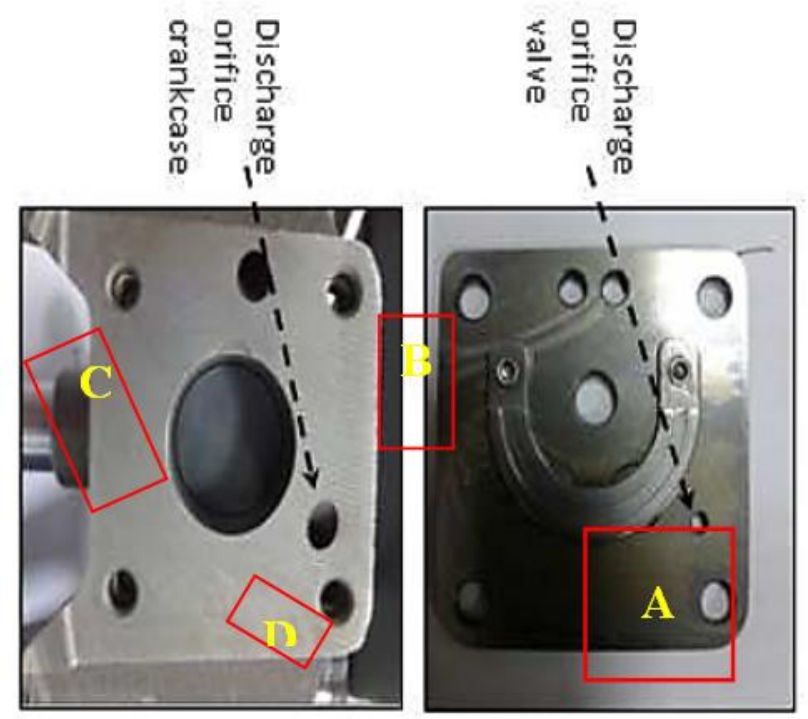

Figure 7: Sensors Identification.

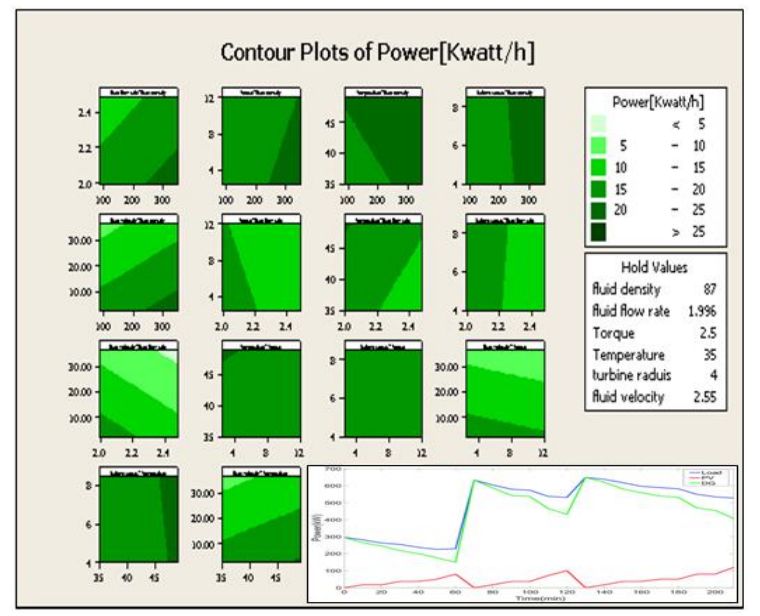

Figure 7.1: Analysis of A, B, C, D Surfaces appeared in Figure 7 via NN

\section{PROPOSED APY IMPLEMENTATION}

The proposed algorithm [APY] observes the deviations of the PY index at significant locations (i.e., A, B, C or D) during working time via specific sensors. The following leaking areas were simulated through Minitab. The first track in the proposed framework was intended to analyse all significant factors that directly affect the product functions and provide immediate error detection to prevent toxic fuel consumption. The data shown in Table 2 is drawn as explained in Figure- 8 to identify the characteristics of the deviation's behavior and to control it via $\mathrm{NN}$, where it reveals many periodic fluctuations that have trends approximately out of standard specification vs. time, which revealed seasonal properties (natural effects of product usage). 


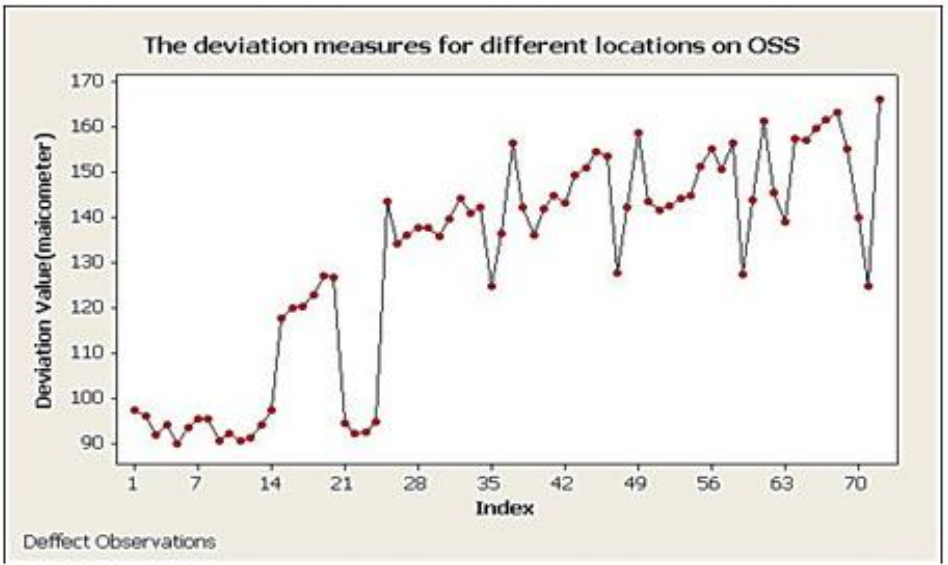

Figure 8: Main Characteristics of Variation Distribution.

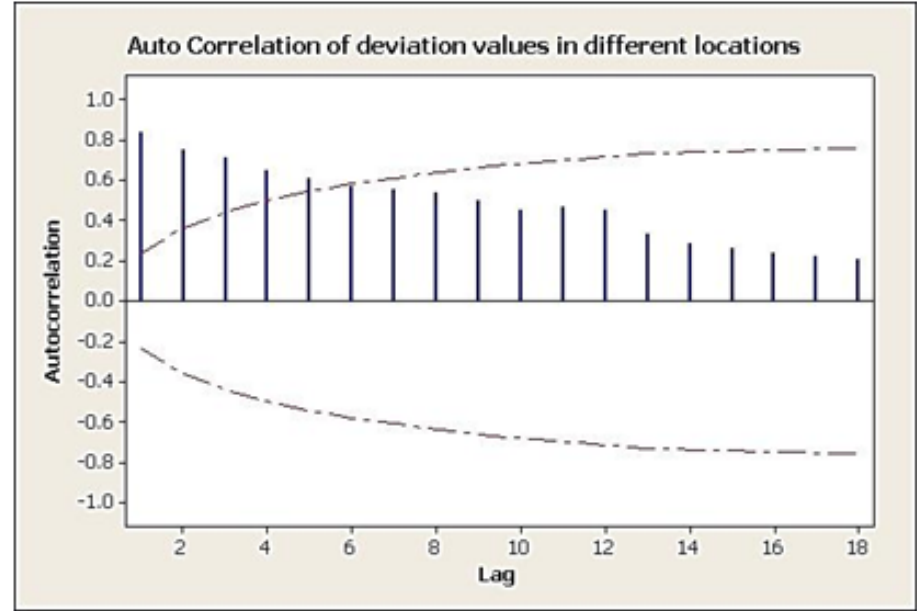

Figure 9: Autocorrelation of Variation Distribution.

The data shown in Figures 8 to 10 represent the cumulative summation of back-and-forth ward responses that control the deviation's trend [19]. It is essential to extract the ACF and PACF for the variation distribution, as shown in Figures 9 and10 respectively, which reveal the parameters are significantly different around zero, to pin at \#18, and are out of the confidence region, which must be within $-0.215 \leq n_{k} \leq 0.215$. Therefore, a stationary case test is mandatory.

\subsection{Stationary test}

This test tackles the data using the logarithmic $\left(\log _{10}\right)$ to fade the trend, which appeared to accurately forecast the output, as shown in Figure- 8 and Figure-11 respectively, for the variation behavior that is essential to feed the neural network model later, and presents a close view of the research objective. The ARIMA chooses parameters by extracting ACF and PACF, which are significantly different around zero until they spike (13) and not within confidence range $-0.215 \leq \eta_{k} \leq 0.215$. L Iung \& Box states the refusal of the main hypothesis $\mathrm{H}_{0}$ in order to Q. stat $=L B Q(T B F)=383.591>x^{2}$ [1,0.01) $=34.83$, Now refuse $\mathrm{H}_{0}: \rho_{1}=\rho_{2}=\Delta \Delta=\rho_{k}=0$ and faith of no fixed in the variation distribution data. 


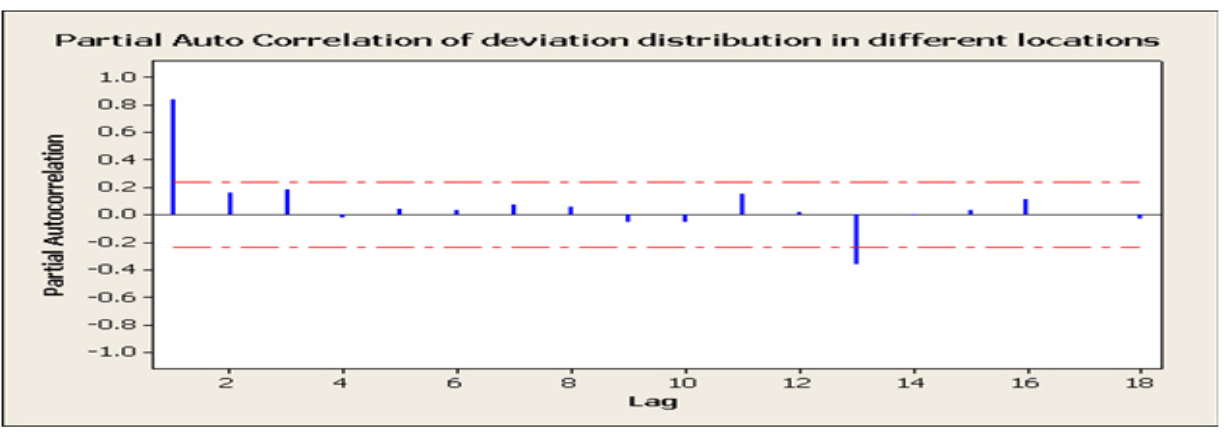

Figure 10: Partial Autocorrelation of Deviation Distribution.

\subsection{Disappear the Trend}

Select the near distribution which decreases the trend and echo the differences for its value until this trend fades: $\nabla Y_{\mathrm{t}(\log 10)}=Y_{\mathrm{t}(\log 10)}-Y_{\mathrm{t}-1 \mathrm{l} \log 10)}$ as illustrated in Figure-12, but the LBQ must be repeated to the first difference to be $L B Q\left(T B F_{\text {first diff }}\right)=32.52<x^{2}{ }_{\left[17_{0} 0.01\right)}=33.41$ : Therefore, we have not taken the second difference for the TBF data and accept $\mathrm{H}_{0}$.

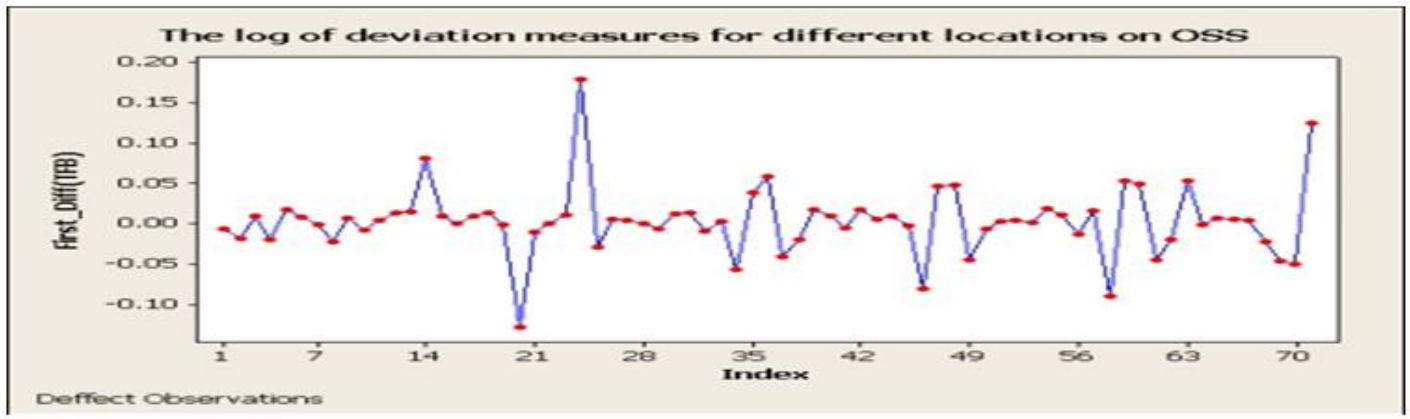

Figure 11: Absence of Trend.

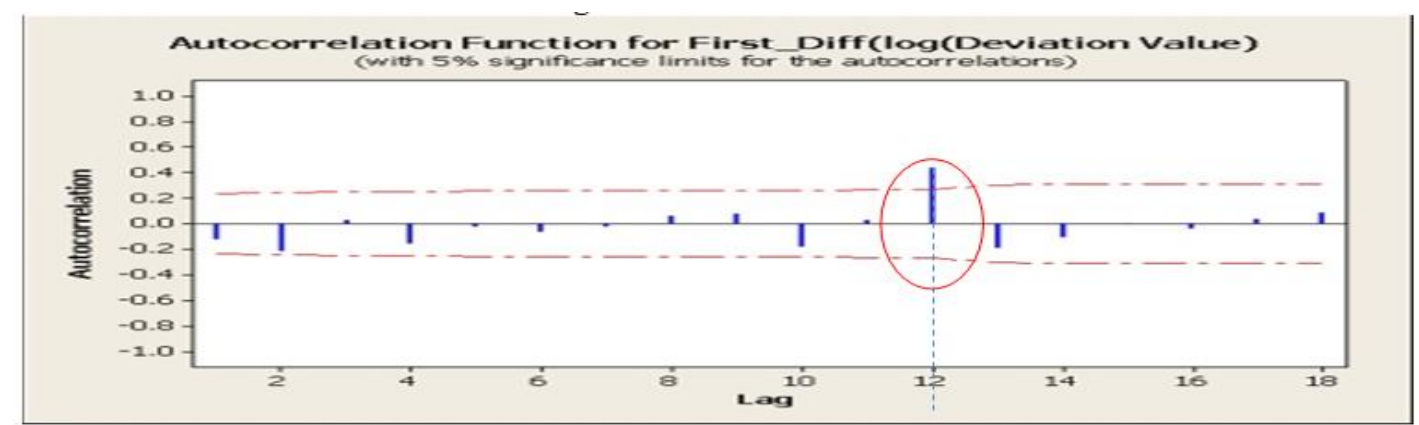

Figure 12: ACF after First Difference. 


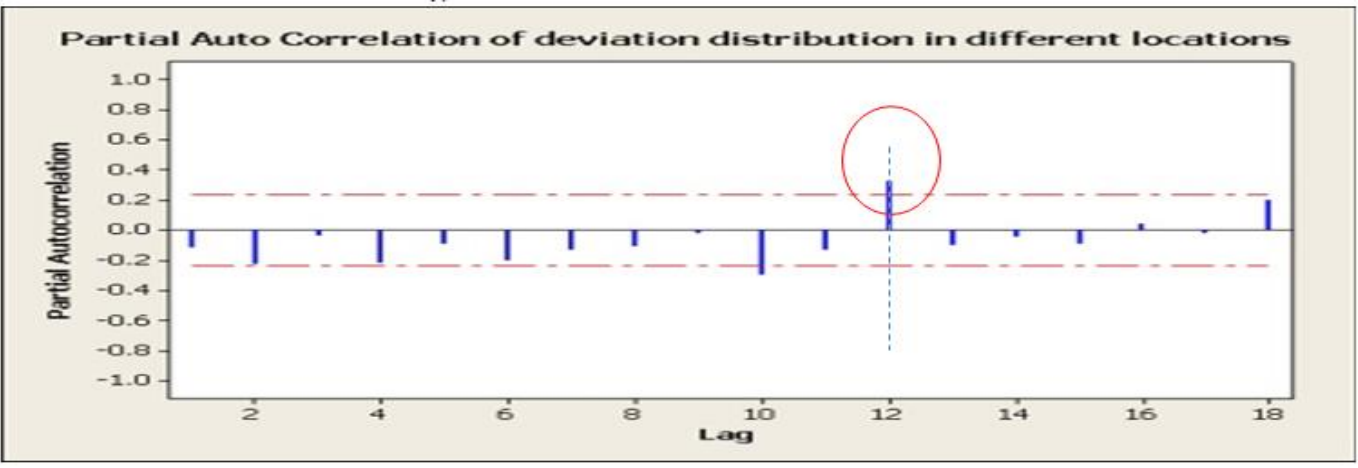

Figure 13: PACF after First Difference.

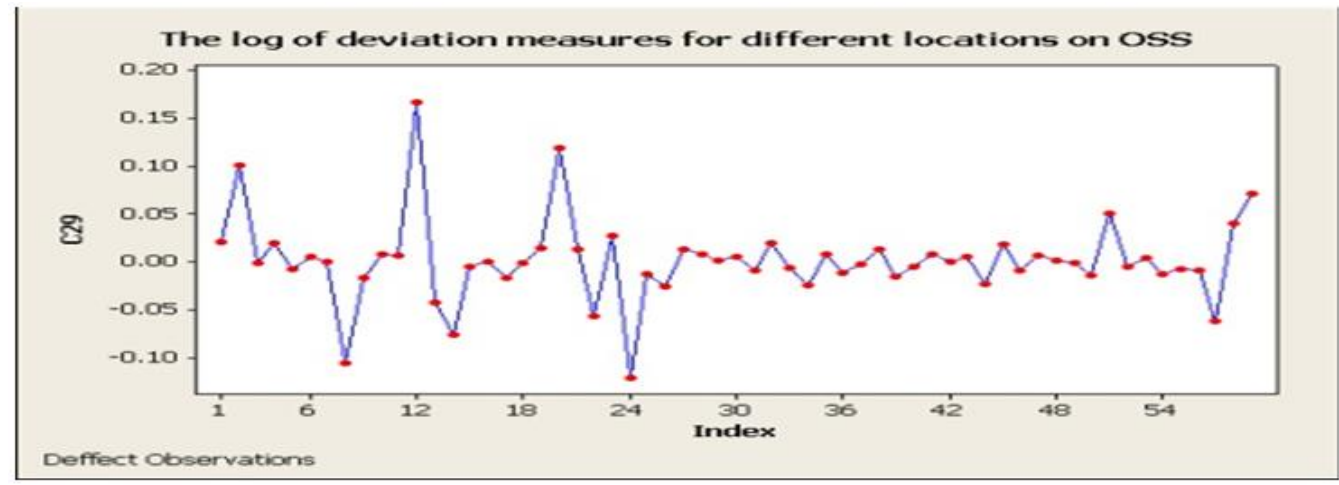

Figure 14: Absence of Trend.

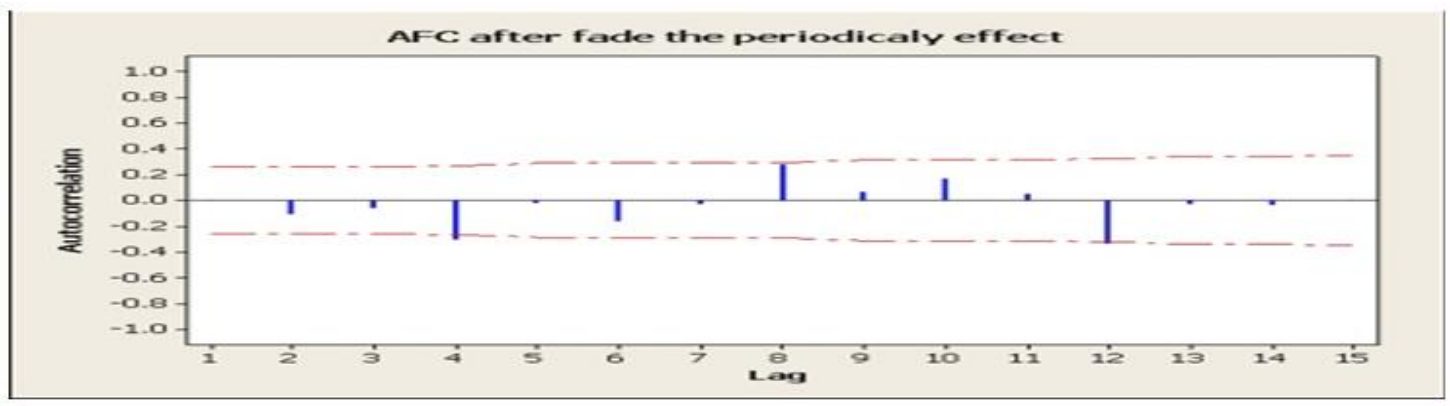

Figure 15: ACF Seasonality First Difference.

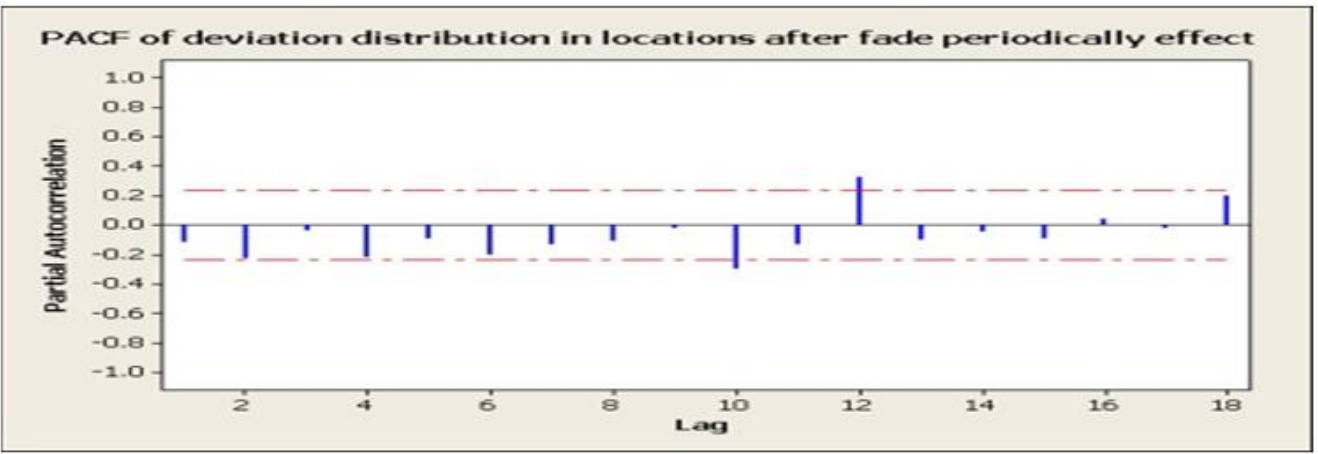

Figure 16: PACF Seasonality First Difference. 
The TBF should be in equivalent to the center of the joints, to prove the absence of the trend, as mentioned in Figure 13. Then, preferably, [d=1], but Figure 12 and Figure 13 explain the seasonal behavior (which appeared for repeated maintenance actions) for the deviation at the location of spike 12. Therefore, the focus was on fading the seasonal attributes and determining the critical span that has maximum probability of malfunction (unreliability) [17] the through time scale $\omega$ :

$L B Q\left(T B F_{\text {first sensonality diff }}\right)=20.63<x^{2}\left[15_{0,01}=30.58\right.$. Therefore, accept the assumption $\mathrm{H}_{0}$ for the seasonal case. If the AFC spreads down toward zero by a power sequence, then the rank of (p) is determined through number of AFC, which is different about zero. However, if the PAFC moves down toward zero by the power sequence, then the rank of $(q)$ is determined through the number of statistical correlation (MA) [33].

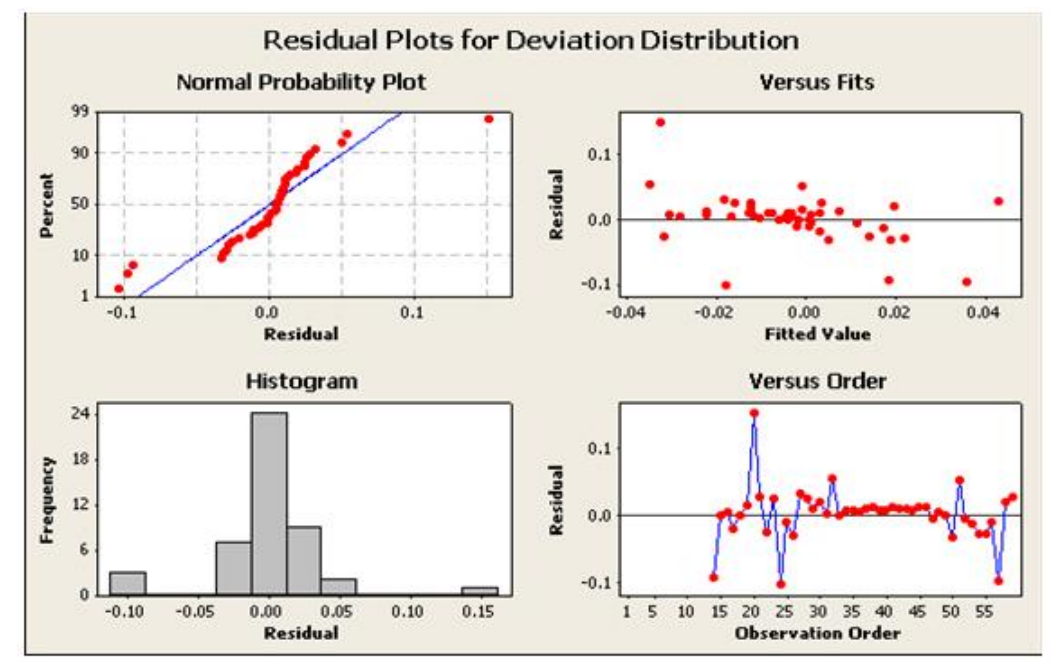

Figure 17: Residual Plots for Seasonality Deviation Behavior.

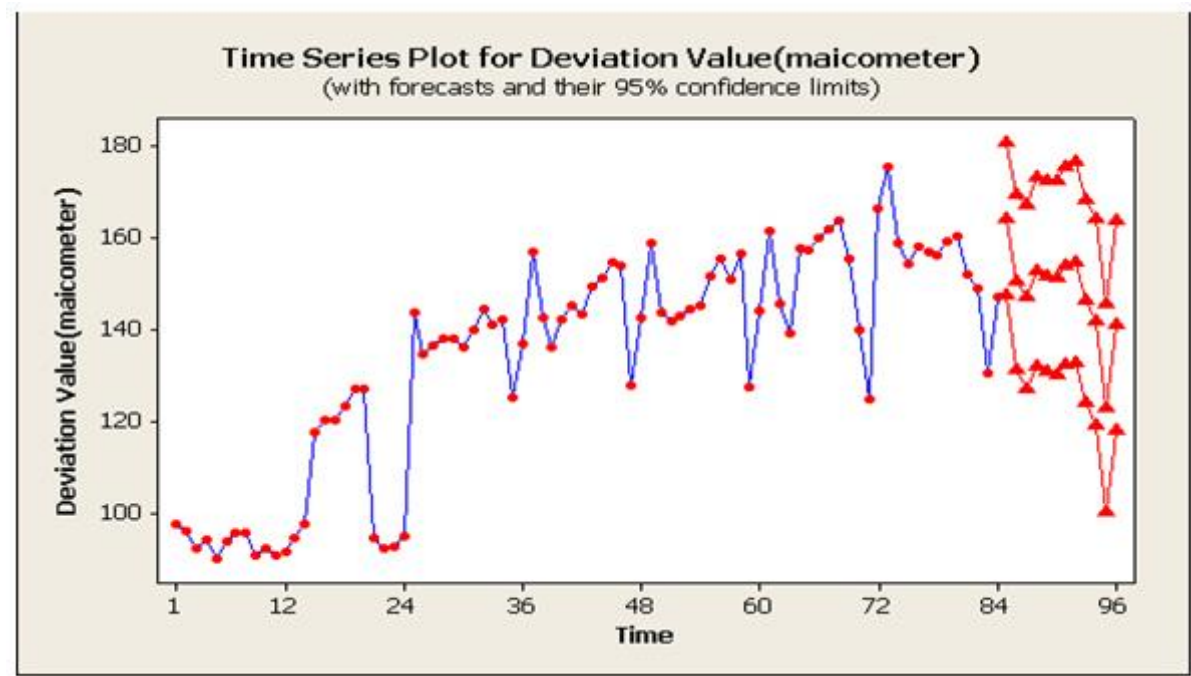

Figure 18: The Prediction Phase for the Deviation Distribution.

** Convergence not met after 26 iterations **

Final Estimates of Parameters 

the Neural Network with Arima Results

$\begin{array}{lrccc}\text { Type } & \text { Coef } & \text { SECoef } & \text { T } & \text { P } \\ \text { AR 1 } & -0.1362 & 0.1649 & -0.83 & 0.414 \\ \text { MA 1 } & 1.0532 & 0.0097 & 108.53 & 0.000 \\ \text { SMA 12 } & 0.9415 & 0.1383 & 6.81 & 0.000\end{array}$

(SMA represents the number of maintenance)

Constant 0.469790 .018325 .760 .000

Differencing: 1 regular, 1 seasonal of order 6, \# of observations: Original series 66, after differencing 53, Residuals: $\mathrm{SS}=5796.49$ (back forecasts excluded), $\mathrm{MS}=136.99 \mathrm{DF}=52$

Modified Box-Pierce (Ljung-Box) Chi-Square statistic

Lag $\quad \begin{array}{llll}\mathbf{6} 24 & 36 & 48\end{array}$

Chi-Square $12.714 .634 .6 *$

DF $\quad 8 \quad 2032$

P-Value $0.124 \quad 0.8010 .347 \quad$ *

$L B Q\left(T B F_{\text {first seasonality diff }}\right)=12.7<x^{2}{ }_{[12,0.01}=26.22$

That shows the non-importance and the model is effective to forecast the variation rate.

Table 3:Forecasted Deviation for Table-2 data

\begin{tabular}{|c|c|c|c|}
\hline \multicolumn{5}{|c|}{ Forecasts the deviation distribution from period 72 [99\% Limits] } \\
\hline Period & Forecast & Lower & Upper \\
\hline 73 & 175.484 & 157.650 & 193.318 \\
\hline 74 & 158.606 & 137.880 & 179.331 \\
\hline 75 & 154.242 & 132.400 & 176.084 \\
\hline 76 & 158.009 & 135.592 & 180.427 \\
\hline 77 & 156.718 & 133.926 & 179.509 \\
\hline 78 & 156.297 & 133.215 & 179.378 \\
\hline 79 & 159.317 & 135.986 & 182.649 \\
\hline 80 & 160.406 & 136.843 & 183.968 \\
\hline 81 & 152.119 & 128.336 & 175.901 \\
\hline 82 & 148.893 & 124.896 & 172.890 \\
\hline 83 & 130.424 & 106.217 & 154.632 \\
\hline 84 & 147.070 & 122.655 & 171.485 \\
\hline
\end{tabular}



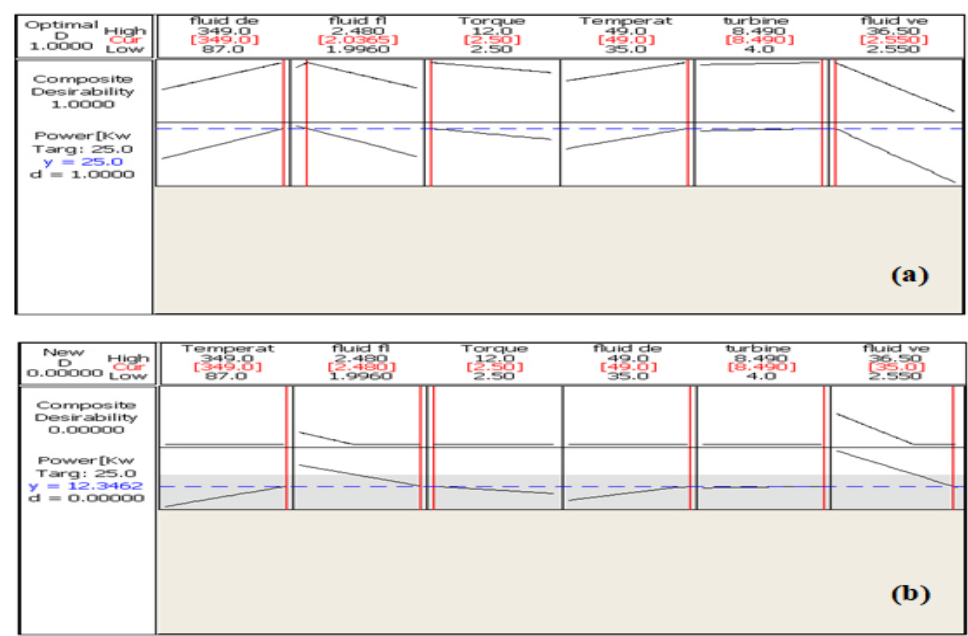

Figure 19: The Optimum Value for Reliability and Maintainability.

The model checks the optimum values to stop working for the factors illustrated in Figure 19-a, while Figure 19-b proves that any deviation of significant factors fall the y to 12.7 as in Eq.6. Rapid maintenance is required and studies of the deviation in working conditions illustrated in Figure 20 to analysis the $\mathrm{PY}_{\mathrm{i}}$. The intake unloaders' diameters are fixed between [10: $13 \mathrm{~mm}$ ] or between [20:24 $\mathrm{mm}$ ] as Safe-Q-Lube suggests, and this achieves the consumption suppression.

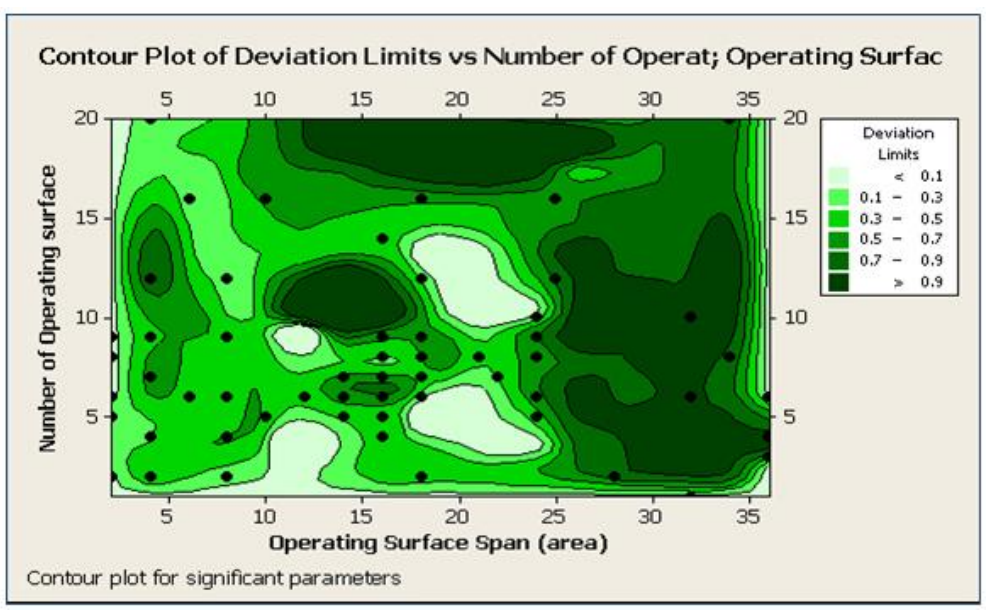

Figure 20: The Fuel Consumption according to APY.

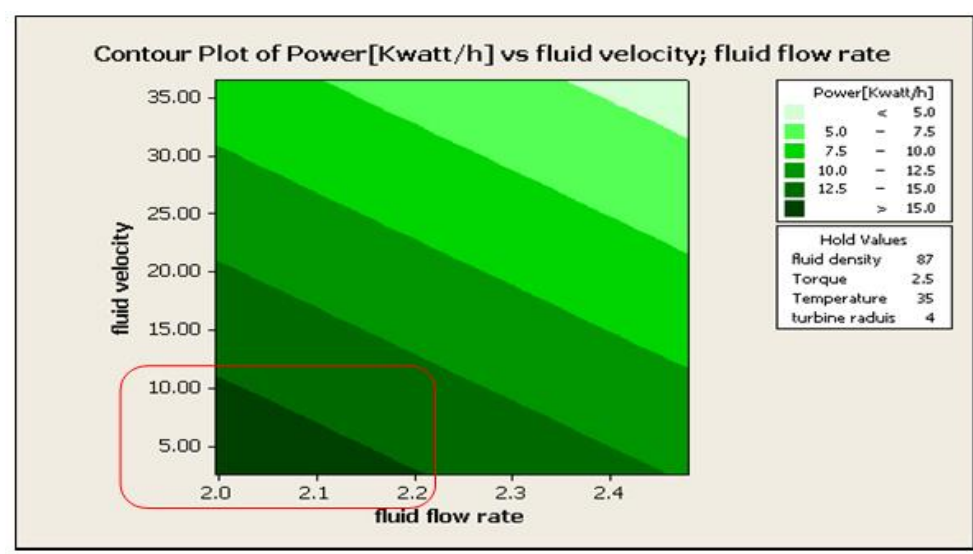

Figure 20.1: The Optimum Replacing Time according to Significant Factors Output. 


\section{CONCLUSIONS}

In this study, the ARIMA time series was used to create short-term forecasting for the behavior of deviations for all the significant factors shown in Figures 4, 4-1 and 6-1, for all selected components which may be involved in causing global warming phenomena, especially in Egypt (where TBL is volatile), and the results were enhanced using an NN model that adopted the Poka-yoke principles known as APY methodology to mitigate the downtime vs. overall time. The forecasted output (ARIMA) and then inputs to NN are compared according to MAE and RMSE as illustrated in Table-4. This work contributes to improving the reliability level of any process' conditions and is helpful in rapid intervention to prevent the malfunction event and enhance the reliability and extend the guarantee by 18 additional times and reduce the malfunctions, as illustrated in Figure 21. This paper has presented a general reliability framework via statistical modeling to control counted data.

Table 4: APY Performance using Correlation Coefficient

\begin{tabular}{|c|c|c|c|c|c|c|c|c|}
\hline \multicolumn{9}{|c|}{ APY performance using MAE and RMSE } \\
\hline Amount of & \multicolumn{2}{|c|}{ Temperature ${ }^{0} \mathrm{C}$} & \multicolumn{2}{|c|}{$\begin{array}{c}\text { Fluid_flow_rate } \\
\mathrm{mm}^{3} / \mathrm{sec}^{-}\end{array}$} & \multicolumn{2}{|c|}{$\begin{array}{c}\text { Fluid_velocity } \\
\text { m/sec. }\end{array}$} & \multicolumn{2}{|c|}{$\begin{array}{c}\text { Fluid_density } \\
\mathrm{N} / \mathrm{m}^{2}\end{array}$} \\
\hline Models & MAE & RMSE & MAE & RMSE & MAE & RMSE & MAE & RMSE \\
\hline ARIMA & 0.8310 & 1.1472 & 0.1401 & 0.2254 & 7.5302 & 13.348 & 1.1815 & 3.2915 \\
\hline NN & 0.6031 & 3.1109 & 0.0640 & 0.2525 & 2.4392 & 3.0302 & 2.2206 & 1.8258 \\
\hline APY & 0.2285 & 0.2501 & 0.0421 & 0.0869 & 2.0413 & 1.8714 & 1.3733 & 0.5164 \\
\hline
\end{tabular}

\begin{tabular}{|l|c|c|c|c|}
\hline \multicolumn{5}{|c|}{ APY performance using correlation coefficients } \\
\hline & \multicolumn{4}{|c|}{ correlation coefficient } \\
\hline Models & Temperature ${ }^{0} \mathrm{C}$ & $\begin{array}{c}\text { Fluid_flow_rate } \\
\mathbf{m m}^{3} / \mathbf{s e c} .\end{array}$ & $\begin{array}{c}\text { Fluid_velocity } \\
\text { m/sec. }\end{array}$ & $\begin{array}{c}\text { Fluid_density } \\
\text { N/m }\end{array}$ \\
\hline ARIMLA & 0.373 & 0.357 & 0.352 & 0.631 \\
\hline NN & 0.755 & 0.746 & 0.937 & 0.757 \\
\hline APY & 0.533 & 0.506 & 0.503 & 0.570 \\
\hline
\end{tabular}

\begin{tabular}{|c|c|c|}
\hline \multicolumn{3}{|c|}{ MAE and RMSE reduced percentage error for all parameters } \\
\hline & \multicolumn{2}{|c|}{ APY } \\
\hline Parameters & MAE reduced error $\%$ & RMSE reduced error \% \\
\hline Temperature & 22.74 & 10.52 \\
\hline Fluid_flow_rate $\mathrm{mm}^{3} / \mathrm{sec}$. & 44.68 & 38.02 \\
\hline Fluid_velocity m/sec. & 64.05 & 61.81 \\
\hline Fluid_density $\mathrm{N} / \mathrm{m}^{2}$ & 30.18 & 32.53 \\
\hline
\end{tabular}

Test Results; the results of testing for ANN used in this work using unseen data are shown in Figure 21. The convergence condition is considered to be achieved when the range between actual values and predicted output is greater than 0.80 , referred to as the limitation of the training data set.

There were no special deviation events; the APY was based on 72 trials of data and continued as illustrated in Figure 22 to Figure 24. 

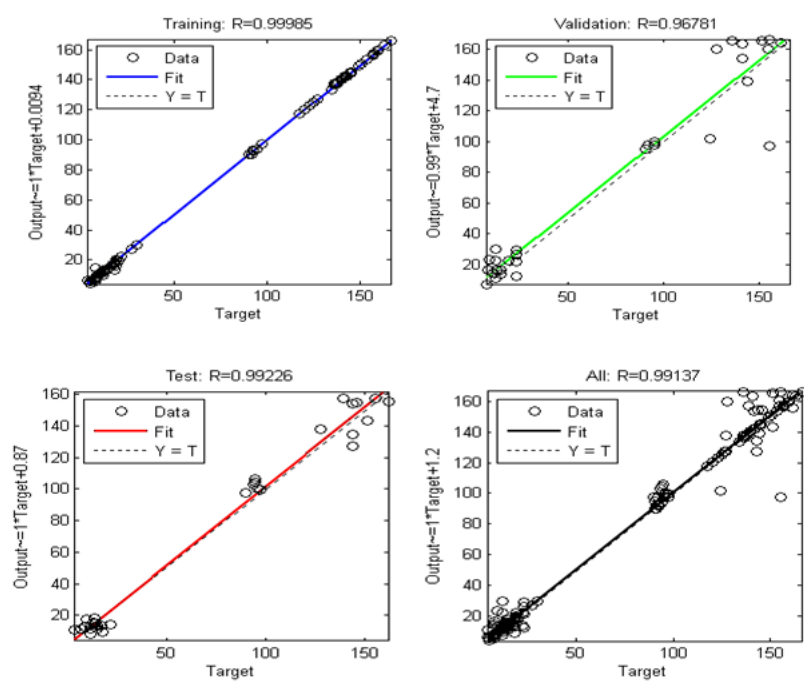

Figure 21: Training Result of Proposed Network.

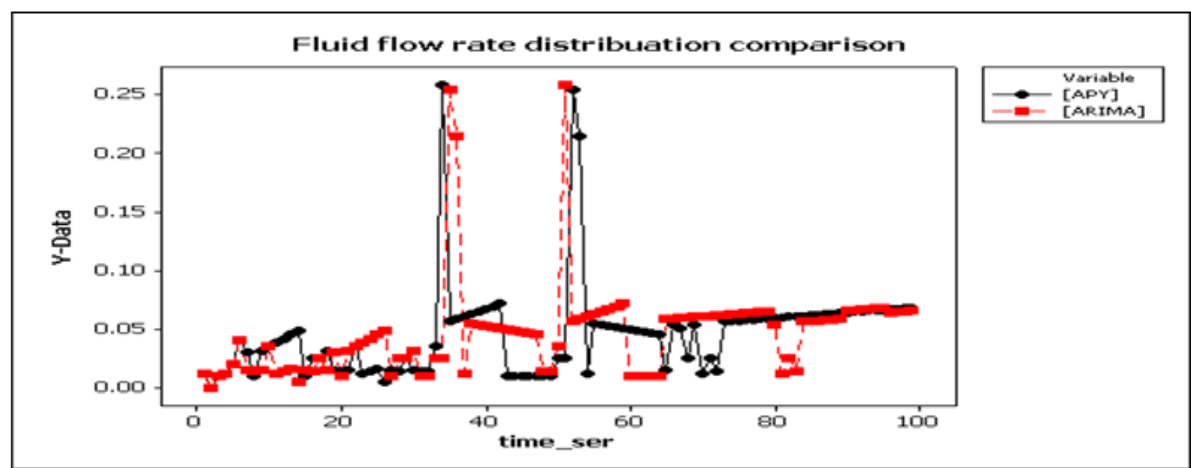

Figure 22: Pearson Correlation $=0.152$ P-Value $=0.134$ for fluid_flow_rate Output.

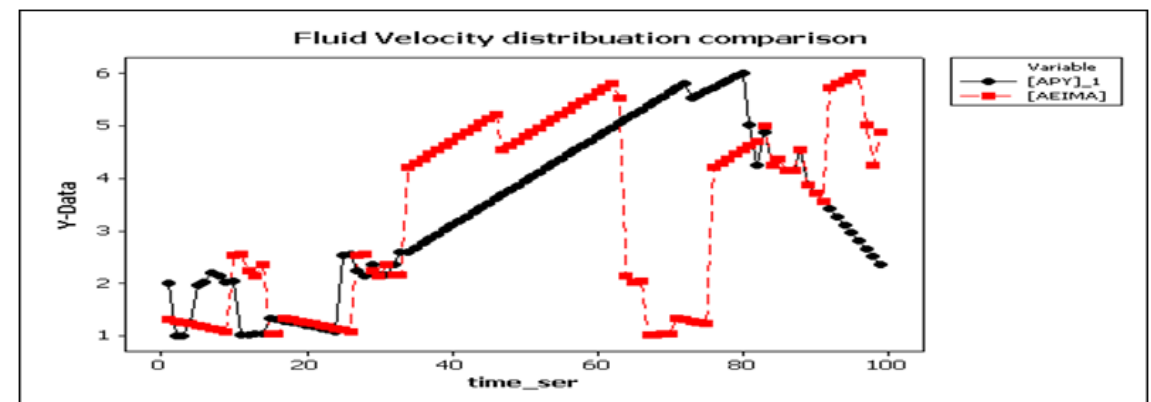

Figure 23: Pearson correlation $=0.371$, P-Value $=0.000$ for fluid_velocity output 


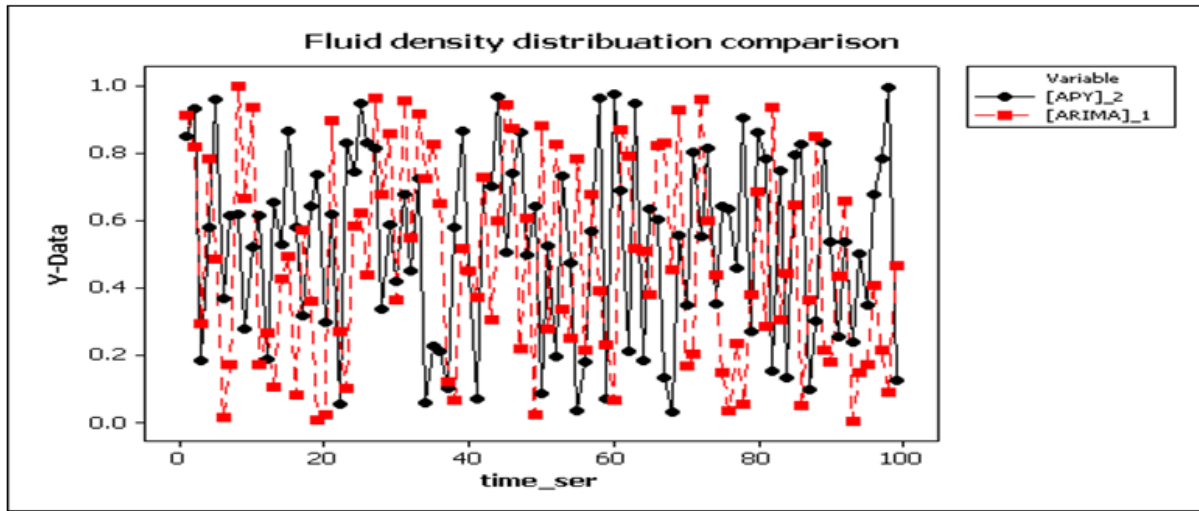

Figure 24: Pearson Correlation= $\mathbf{- 0 . 0 6 4}, \mathbf{P}$-Value $=\mathbf{0 . 5 3 2}$ for fluid_density output

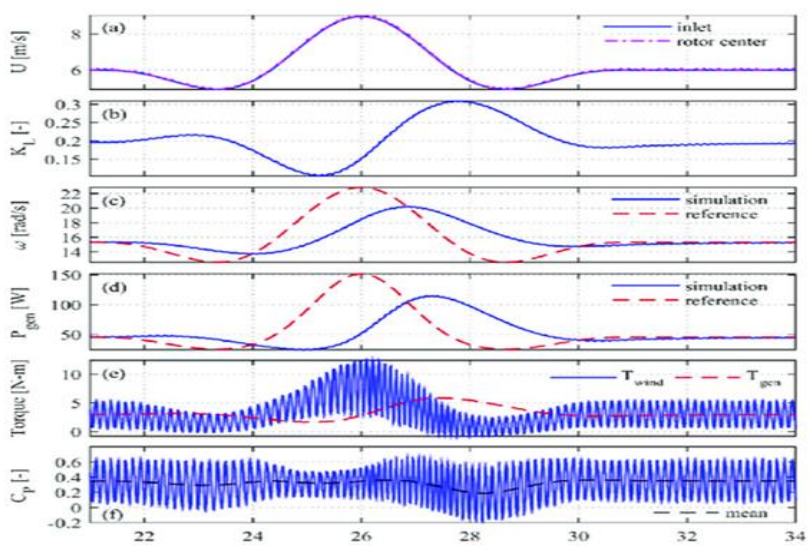

Figure 25: Analysis of Poka-Yoke index for Power Generated.

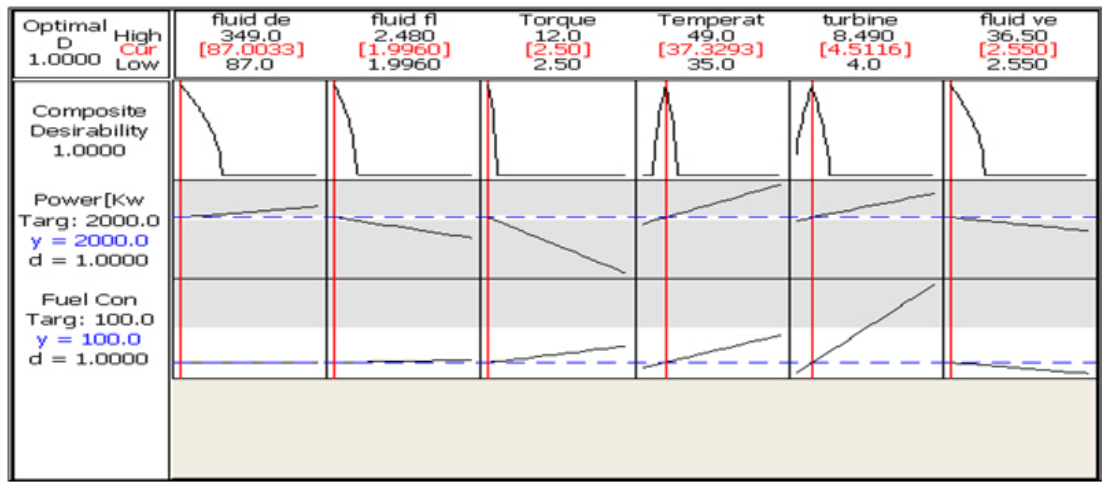

Figure 26: The Optimum Consumption and Generated Power. 

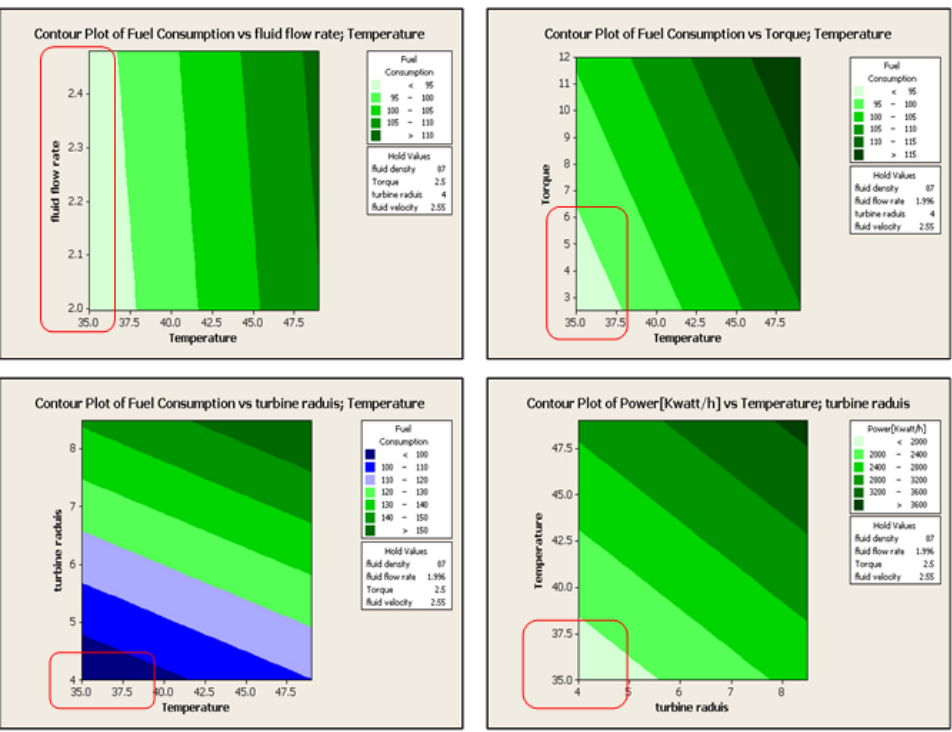

Figure 26.1: The Contour Plot for Fuel Consumption and Power Generated.
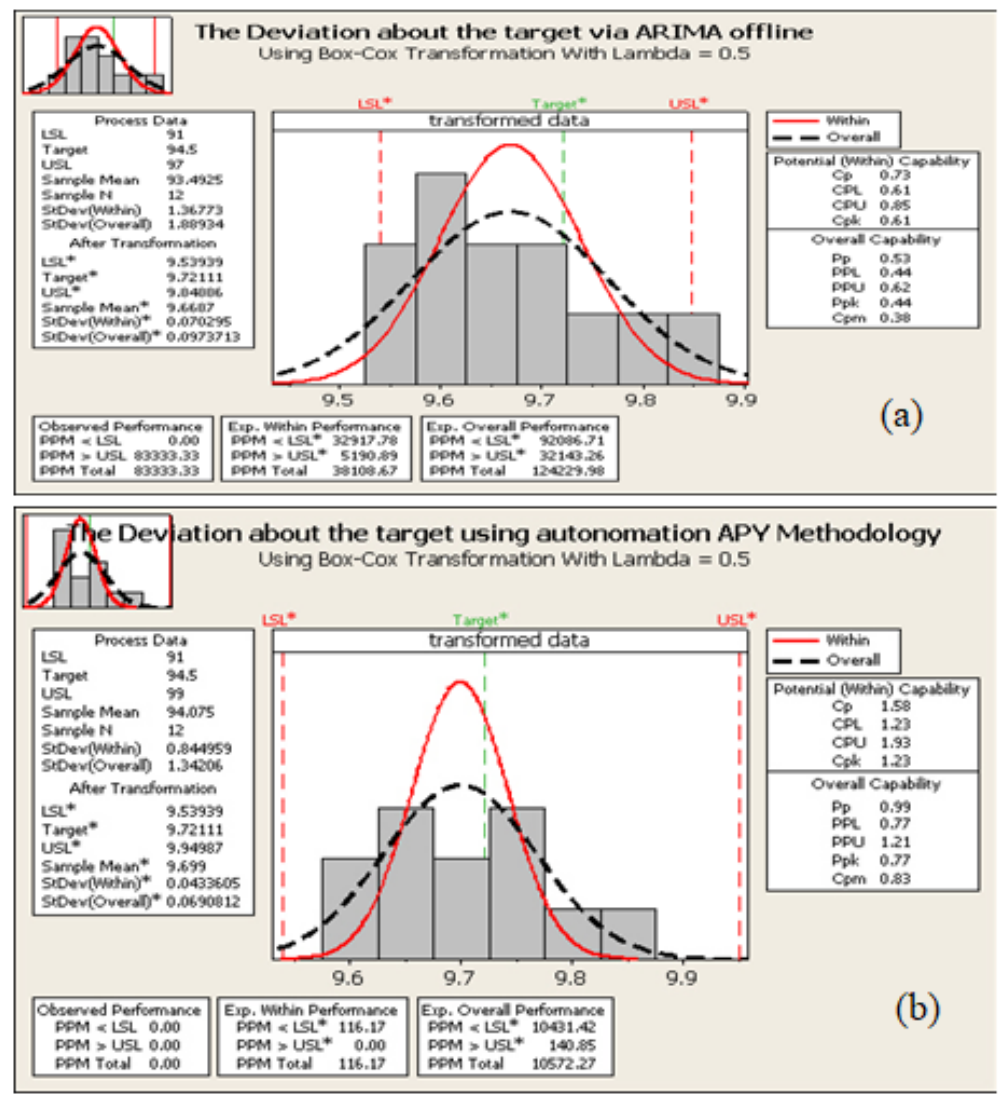

Figure 27: Stages of Implementing APY Testing Methodology. 


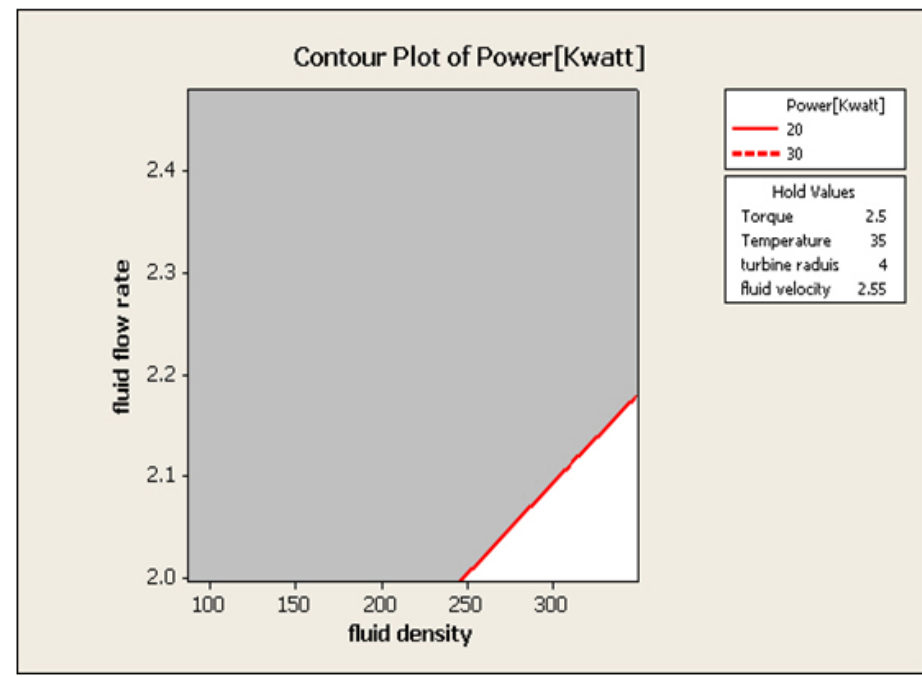

Figure 28: Contour of Power [Kwatt/h].

\section{ACKNOWLEDGMENTS}

This research was funded by the Deanship of Scientific Research at Princess Nourah bint Abdulrahman University through the Fast-track Research Funding Program. The work reported in this article has been conducted while some of the researchers are affiliated with Princess Nourah bint Abdulrahman University.

Conflicts of Interest: The authors declare no conflict of interest.

\section{REFERENCES}

1. Ahmed M. Abed. Adjust Jidoka Occupational Fatigue to Reduce Idle times using Data Mining as Lean Tool. EIJEST, The Egyptian International-Journal of Engineering Science and Technology2016; Volume 19 (2);pp. 312318http://www.eijest.zu.edu.eg/index.php/EIJEST/issue/view/94

2. Tan M, Tan L, Dara S, Mayuex C. Online defect prediction for imbalanced data. In: Proc. Int'l Conf. on Softw. Eng. (ICSE'13 SEIP), $p$ (To appear), 2015

3. Zhang H, Zhang X. Comments on 'data mining static code attributes to learn defect predictors'. IEEE Trans SoftwEng2007; Volume 33(9); pp. 635-637

4. Y. B. Wijaya, S. Kom, and T. A. Napitupulu. Stock price prediction: Comparison of Arima and artificial neural network methods-an Indonesia stock's case. in Proceedings of the 2nd International Conference on Advances in Computing, Control and Telecommunication Technologies (ACT'10), Jakarta, Indonesia, 2010; pp. 176-179

5. B. Johnston, L. B. Maguire, and T. M. MciGinnity. Downstream performance prediction for a manufacturing system using NN and six-sigma improvement techniques. Robotics and Computer-Integrated Manufacturing2009; Volume. 25 (3); pp. 513-521.

6. Antony J., Snee R., and Hoeril R. Lean Six Sigma: Yesterday, Today and Tomorrow. International Journal of Reliability \& Reliability Management 2017; Volume 34 (7), pp. 1073- 1093, doi:10.1108/IJQRM-03-2016-0035.

7. M. M. Mostafa. Forecasting stock exchange movements using neural networks: empirical evidence from Kuwait. Expert Systems with Applications 2010;Volume.37 (9); pp.6302-6309.

8. Bonvoisin J., Stark R., Seliger G. Field of Research in Sustainable Manufacturing. In: Stark R., Seliger G., Bonvoisin J. (eds) Sustainable Manufacturing. Sustainable Production, Life Cycle Engineering and Management. Springer, Cham 2017. 
9. O. Adewumi and A. Moodley. Comparative results of heuristics for portfolio selection problem. in Proceedings of the IEEE Conference on Computational Intelligence for Financial Engineering \& Economics (CIFEr '12), pp. 1-6, New York, NY, USA, March 2012.

W. C. Chen, G.-L., Fu, P.-H. Tai, and W.-J. Deng, Process parameter optimization for MIMO plastic injection molding via soft computing. Expert Systems with Applications 2009; Volume 36; pp. 114-1122.

10. Heider, D., Piovoso, M. J. and Gillespie Jr, J. W. Application of a neural network to improve an automated thermoplastic towplacement process. Journal of Process Control 2002; Volume 12;pp. 101-111.

11. C. Cho, D. D. Kim, J. Kim, D. Lim, and S. Cho. Early prediction of product performance and yield via technology benchmark. IEEE "Custom Integrated Circuits Conference (CICC)"2008; pp. 205-208,.

12. Freitas J. G., Costa H. G., and Ferrazi F. T. Impacts of Lean Six Sigma over Organizational Sustainability: A Survey Study. Journal of Cleaner Production2017; Volume 156; pp. 262-275, doi:10.1016/j.jclepro.2017.04.054

13. Gupta V., Narayanamurthy G., and Acharya P. Can Lean Lead to Green? Assessment of Radial Tyre Manufacturing Processes Using System Dynamics Modeling. Computers and Operations Research2018; Volume 89; pp. 284-306, doi:10.1016/j.cor.2017.03.015.

14. S. Herbold. Comments on ScottKnottESD in response to "An empirical comparison of model validation techniques for defect prediction models". IEEE Transactions on Software Engineering 2017; Volume 43(11); pp. 1091-1094.

15. K. Aishwarya Raghavi et al. Human Iris Recognition Using Fuzzy Neural Concepts. 2011 International Conference on Bioscience, Biochemistry and Bioinformatics IPCBEE, Volume.5 IACSIT Press, Singapore2011.

16. Y. B. Wijaya, S. Kom, and T. A. Napitupulu. Stock price prediction: Comparison of Arima and artificial neural network methods-an Indonesia stock's case. in Proceedings of the 2ndInternational Conference on Advances in Computing, Control and Telecommunication Technologies (ACT '10), pp. 176-179, Jakarta, Indonesia, December 2010.

17. L. Madeyski and M. Jureczko. Which process metricscan significantly improve defect prediction models? anempirical study. Software Quality Journal 2015; Volume 23(3); pp.393-422.

18. M. Sameh Ibrahim, M. A. R. Mansour, A. M. Abed. Improve six-sigma management by forecasting production quantity using image_verification reliability tool. International journal of advance in engineering and technology (IJAET) 2011; Volume 1(53); pp332-342, ISSN 2231-1963.

19. Muhamad Safiih Lola and et al. Improving The Performance Of Ann-Arima Models For Predicting Water Reliability In The Offshore Area Of Kuala Terengganu, Terengganu, Malaysia. Journal of Sustainability Science and Management2018; Volume 13(1); pp 27: 37.

20. J. Sterba and K. Hilovska. The implementation of hybrid ARIMA neural network prediction model for aggregate water consumption prediction. Aplimat_Journal of Applied Mathe-matics 2010; Volume 3(3); pp.123-131.

21. Reuben Feinman, Ryan R. Curtin, Saurabh Shintre, and Andrew B. Gardner. Detecting adversarial samples from artifacts, 2017. Technical Report. http://arxiv.org/abs/1703.00410.

22. B. Zhu, B. Baesens, A. e. Backiel, and S. K. vandenBroucke. Benchmarking sampling techniques for imbalance learning in churn prediction. Journal of the Operational Research Society 2018; Volume 69( 1); pp. 49-65.

23. S. Kaparthi, and N. C Suresh. Machine-component cell formation in Group technology: A neural network approach. International Journal of Production research1992;Volume 30(6); pp. 1353 - 1367.[Online], Available: http://www.tandfonline.com/doi/abs/10.1080/00207549208942961\#preview [Sept. 1, 2013] 
24. Qiu, M., \& Song, Y. Predicting the Direction of Stock Market Index Movement Using an Optimized Artificial Neural Network Model. PLoS ONE2016; Volume 3(11); pp. 1-11.

25. N. Merh, V. P. Saxena, and K. R. Pardasani. A comparison between hybrid approaches of ANN and ARIMA for Indian stock trend forecasting. Journal of Business Intelligence 2010; Volume 3(2); pp. $23-43$.

26. Xue, T., Peng, Q. F., Huang, G. J., et al. Fault Analysis and Evaluation Method of Ele-vator Door System Based on Fault Tree. Automation \& Information Engineering 2015; Volume 6; pp. 34-36.

27. K. Julian, J. Lopez, J. Brush, M. Owen, and M. Kochenderfer. Policy compression for air craft collision avoidance systems. In Proc. 35th Digital Avionics System Conf. (DASC) 2010; pp. 1-10.

28. Uluskan M. A Comprehensive Insight into the Six Sigma DMAIC Toolbox. International Journal of Lean Six Sigma 2016; Volume 7( 4); pp. 406-429, doi:10.1108/IJLSS-10-2015-0040.

29. Uluskan M. Analysis of Lean Six Sigma Tools from a Multidimensional Perspective. Total Reliability Management \& Business Excellence2017, doi:10.1080/14783363.2017.1360134.

30. S Ajakaiye, A. B Adeyemo, A. O Osofisan, and O. P A Olowu, O. P. A. Analysis of Poultry Birds production performance usingArtificial Neural Networks. Asian Journal of Information Technology its applications 2006; Volume 5(5).[Online], Avaialable:http://docsdrive.com/pdfs/medwelljournals/ajit/2006/522- 527.pdf [Sept., 12, 2013

31. Verrieir B., Rose B., and Caillaud E. Lean and Green Strategy: the Lean and Green House and Maturity Deployment Model. Journal of Cleaner Production2016; Volume 116; pp. 150-156, doi:10.1016/j.jclepro.2015.12.022.

32. M. Sridhar 1, K. Padma Raju2, Ch. Srinivasa Rao3, D. Venkata Ratnaml. Prediction and Analysis of Rain Attenuation using ARIMA Model at Low latitude Tropical Station. International Journal of Advanced Research in Electrical, Electronics and Instrumentation Engineering 2013; Volume2( 7).

33. Huang, S. H. and Zhang, H. -C. Neural-expert hybrid approach for intelligent manufacturing: a survey. Computer in Industry 1995; Volume 26; pp. 107-126.

34. W. Ma, S. Fang, B. Su, X. Xue, M. Li.. (2017). "Second-law-based analysis of vapor-compression refrigeration cycles": analytical equations for COP and new insights into features of refrigerants Energy Convers Manage 2017; Volume 138; pp. 426-434.

35. R. SherlineJesie. Multi-model Authentication System using Artificial Neural Network. International Conference on Emerging Technology Trends (ICETT), Proceedings by International Journal of Computer Applications 2011, (IJCA).

36. L. Pulina and A. Tacchella. Challenging SMT solvers to verify neural networks. AI Communications 2012; Volume 25(2); pp. $117-135$.

37. Z. Huang, H. Yu, Z. Peng, M. Zhao., (2015). "Methods and tools for community energy planning: a review Renew Sustain Energy.", Rev 2015; Volume 42; pp. 1335-1348.

38. Zhang, A. Reliability improvement through Poka-Yoke: from engineering design to information system design. Int. J. Six Sigma and Competitive Advantage2014; Volume 8 (2); pp.147-159.

39. Luxhoj, et al., 1996Time series forecasting by combining RBF networks, certainty factors, and the Box-Jenkins model 1996; Volume 10 (2), pp.149-168 •

40. Lazonick, W. and Prencipe, A. Dynamic capabilities and sustained innovation: strategic control and financial commitment at Rolls-Royce Plc. Industrial and Corporate Change 2005; Volumr14; pp. 501-542. 
41. "Reduction of Assembly Time in RAPMAN 3.13 d Printer by Redesign of One of the Eight Corners by using DFMA Method", International Journal of Sales \& Marketing Management (IJSMM), Vol. 5, Issue 6, pp. 1-6

42. "Inventory Management Practices Followed in Coconut Oil Mills in Western Tamil Nadu”, International Journal of Humanities and Social Sciences (IJHSS), Vol. 5, Issue 2, pp. 23-28

43. "The Integration of Lean Manufacturing and Lean Maintenance to Improve Production Efficiency”, IJMPERD, Vol. 9, Issue 1, pp. 601-612

44. "Role of Lean Manufacturing Leadership on Technology Transfer in India: A Facet of Manufacturing Industries with Reference to Guntur District, Andhra Pradesh", IJMPERD, Vol. 8, Issue 3, pp. 257-266 